\title{
Máirtín Ó Cadhain agus foirm an ghearrscéil: litir ó Mháirtín Ó Cadhain chuig Seosamh Ó Duibhginn, Eanáir 1947
}

\author{
AISLING NÍ DHONNCHADHA \\ (Ollscoil Mhá Nuad) \\ MÁIRÍN NIC EOIN \\ (Coláiste Phádraig, Droim Conrach)
}

\section{Réamhrá}

\section{An comhthéacs beathaisnéiseach}

Scríobh Máirtín Ó Cadhain an litir atá á foilsiú anseo chuig Seosamh Ó Duibhginn ar 6 Eanáir 1947, tar éis don Duibhginneach dréacht de ghearrscéal dá chuid a chur faoina bhráid lena thuairim agus a chomhairle a fháil ina thaobh. Tá an litir seo caomhnaithe i bPáipéir Uí Dhuibhginn i gCartlann an Choláiste Ollscoile, Baile Átha Cliath, sa chomhad P172/378. ${ }^{1}$

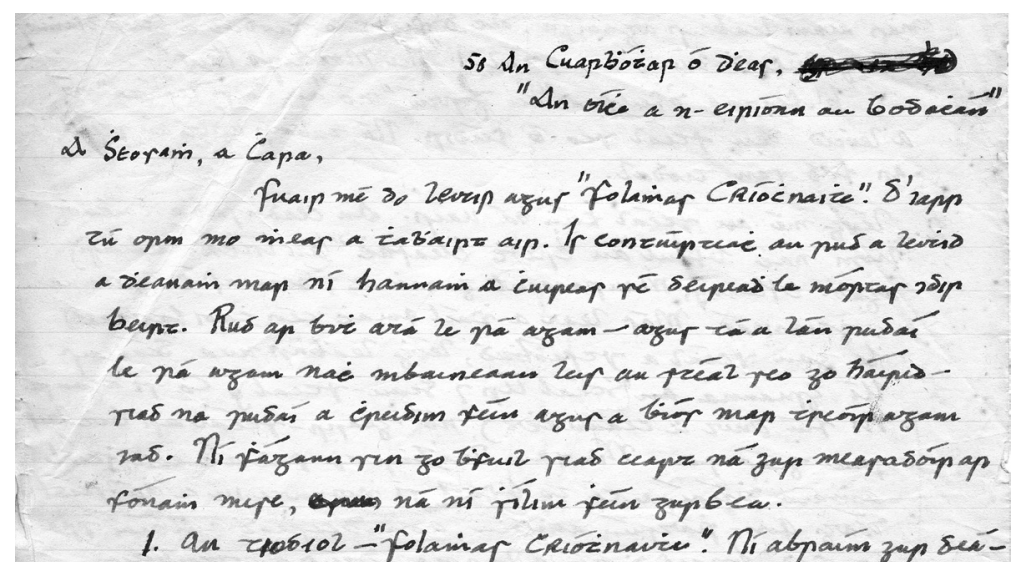

Tús na litreach ó Mháirtín Ó Cadhain chuig Seosamh Ó Duibhginn. Foilsithe le caoinchead Chartlann an Choláiste Ollscoile, Baile Átha Cliath. ${ }^{2}$

${ }^{1}$ Ba mhaith linn ár mbuíochas a ghabháil leis an Dr Mícheál Briody a chuir an litir ar ár súile dúinn, a spreag muid le tabhairt faoin aiste léirmhínithe agus a chuidigh linn le brí pointí áirithe téacs a scaoileadh. Ba mhaith linn ár mbuíochas a chur in iúl freisin do na daoine agus na heagraíochtaí seo a leanas: Iontaobhas Uí Chadhain a thug cead dúinn an litir a fhoilsiú; Kate Manning agus foireann Chartlann an Choláiste Ollscoile, Baile Átha Cliath; Tina Byrne, Cartlann RTÉ; agus Jane Maxwell agus foireann Chartlann Choláiste na Tríonóide.

${ }^{2}$ UCDA P172/238. 
Bhí an bheirt fhear tar éis aithne a chur ar a chéile i gCampa Géibhinn an Churraigh ag tús na ndaichidí. Bhí Ó Duibhginn, arbh as deisceart Ard Mhacha dó, sa Churrach ó 17 Feabhra 1940 go 16 Samhain 1943, agus d'fhreastail sé ar ranganna Gaeilge an Chadhnaigh ansin. Bhí an Cadhnach sa Churrach ó Aibreán 1940 go dtí Iúil 1944. Bhí teagmháil rialta ag an mbeirt fhear lena chéile ag deireadh na ndaichidí, agus bhí Ơ Duibhginn ar dhuine den mheitheal a chuidigh le Ó Cadhain lámhscríbhinn Cré na cille a réiteach le cur isteach ar chomórtas an Oireachtais 1947. ${ }^{3} \mathrm{D}$ 'athraigh an gaol comhghleacúil a bhí eatarthu sna blianta ina dhiaidh sin, agus tá an t-athrú seo le feiceáil sa chomhfhreagras idir an bheirt fhear atá caomhnaithe i bPáipéir Uí Dhuibhginn i gCartlann an Choláiste Ollscoile, Baile Átha Cliath. Bhí siad fós mór le chéile, áfach, nuair a scríobhadh an litir seo agus dhá litir eile gan dáta (ach ar léir gur scríobhadh go gairid i ndiaidh na litreach seo iad) atá le fáil taobh léi i bPáipéir Uí Dhuibhginn. Is é mórluach na litreach ná go dtugann sí spléachadh fíorshuimiúil dúinn ar dhearcadh liteartha Uí Chadhain i gcomhthéacs comhfhreagrais phríobháidigh nach raibh aon aidhm eile leis seachas breithiúnas liteartha a thabhairt agus comhairle a leasa a chur ar chara leis.

Ba dhuine é Ó Duibhginn a raibh ceird na scríbhneoireachta á foghlaim aige ag an am, agus níorbh é an Cadhnach an t-aon duine a bhfuair sé comhairle uaidh. Ina shaothar cuimhní cinn, $A g$ scaoileadh sceoil, luann sé an tábhacht a bhain leis an gcomhairle a d'fhaigheadh sé go rialta ón Athair Eric Mac Fhinn, eagarthóir na hirise Ar Aghaidh, nuair a chuireadh sé dréachtaí chuige siúd le foilsiú san iris: 'Scrúdaíodh sé gach focal agus gach abairt. Cháineadh sé agus mholadh sé. Deireadh sé liom gur chóir dom an leabhar seo agus an leabhar sin a léamh. Bhíodh cuid de na litreacha an-fhada. Ba aistí léirmheastóireachta iad dáiríre' ${ }^{4}$ Ní thagraíonn sé don chomhairle a d'fhaigheadh sé ó Ó Cadhain ar chor ar bith, cé gur macalla ar fhocail Uí Chadhain féin chuige sa litir atá á foilsiú anseo an clabhsúr a chuireann sé ar a chuntas ar an gcomaoin a chuir Mac Fhinn air: 'Is é an dearmad is mó d'fhéadfadh dochar a dhéanamh do scríbhneoir é bheith den tuairim go bhfuil a chuid oibre gan locht. Níl rud ar bith chomh maith nach féidir a fheabhsú tuilleadh'.5

Tar éis dó blianta duaisiúla a chaitheamh i mbun postanna de chineálacha éagsúla $\mathrm{i}$ ndiaidh dó teacht amach as Campa an

\footnotetext{
${ }^{3}$ Tá an t-eolas beathaisnéiseach a thugtar anseo bunaithe ar na cuntais a thugann Diarmuid Breathnach agus Máire Ní Mhurchú ar Ó Cadhain agus Ó Duibhginn in Beathaisnéis 4 agus 6, ar fáil ag www.ainm.ie.

${ }^{4}$ Seosamh Ó Duibhginn, Ag scaoileadh sceoil (Baile Átha Cliath, 1962), 81.

${ }^{5}$ Ibid., 81-2.
} 
Churraigh - sclábhaíocht feirme agus obair thógála ina measc - fuair Ó Duibhginn post páirtaimseartha mar fhear foirnéise i gColáiste Mobhí agus thosaigh sé ag scríobh aistí Gaeilge d'irisí agus do nuachtáin. Is le hiriseoireacht agus le tionscnaimh foilsitheoireachta agus léinn, seachas leis an scríbhneoireacht chruthaitheach, a chuaigh sé ina dhiaidh sin. Ceapadh ina bhainisteoir ar iris Chonradh na Gaeilge Feasta é nuair a bunaíodh an iris sa bhliain 1948, agus rinneadh eagarthóir de an bhliain ina dhiaidh sin. Lean sé de chúram Feasta, idir bhainistíocht agus eagarthóireacht, go dtí an bhliain 1962, nuair a ceapadh ina eagarthóir Gaeilge ar Scéala Éireann é. Cé gur fhoilsigh Ó Duibhginn gearrscéalta thall is abhus agus gur roghnaigh Tomás de Bhaldraithe gearrscéal leis dar teideal 'An crotach' don díolaim Nuascéalaiocht: 1940-1950, ${ }^{6}$ níl aon amhras ná gurbh fhearr a d'oir scóip agus dúshláin réimse na hiriseoireachta i gcoitinne dá bhuanna agus dá éirim scríbhneoireachta.

Níl teacht againn anois ar an mbundréacht den scéal a sheol Ó Duibhginn chuig Ó Cadhain, ach tá an chuma ar an leagan a foilsíodh in eagrán mhí Iúil 1948 de Feasta, gur fhéach sé le comhairle Uí Chadhain a chur i bhfeidhm. ${ }^{7}$ D'athraigh sé an teideal, mar shampla, ó 'Folamhas críochnaithe' go dtí 'An chois leointe', mar a mholtar sa litir. Braithimid nach é a tionchar ar Ó Duibhginn an ghné is inspéise den litir, áfach, ach an léargas a thugann sí ar dhearcadh liteartha Mháirtín Uí Chadhain ag tús na bliana 1947. Faoi Eanáir na bliana 1947 bhí an cnuasach An braon broghach críochnaithe agus i lámha na bhfoilsitheoirí, An Gúm. ${ }^{8}$ Bheadh Cré na cille á ullmhú don Oireachtas níos déanaí an bhliain chéanna. Bhí scéalta a d'fhoilseofaí ina dhiaidh sin sa chnuasach Cois caoláire á bhfoilsiú de réir a chéile in irisí agus i nuachtáin ó 1945 ar aghaidh. ${ }^{9}$ Bhí obair athdhréachtaithe á déanamh aige ar scéalta ar leith, agus i gcásanna áirithe níorbh ionann an leagan a foilsíodh i dtréimhseachán agus an leagan a foilsíodh ina dhiaidh sin sa chnuasach..$^{10}$ Tá an chuma ar an scéal gur lean an t-athshaothrú uaireanta fiú amháin agus an t-ábhar curtha chun bealaigh chuig foilsitheoir aige. Mar shampla, ní hionann an leagan den scéal ríghairid 'Glantachán earraigh', a dtagraítear go sonrach dó sa litir chuig Ó Duibhginn, a foilsíodh san Irish Independent ar 23 Nollaig 1946 agus a foilsíodh ina dhiaidh sin

\footnotetext{
${ }^{6}$ Tomás de Bhaldraithe (eag.), Nuascéalaíocht: 1940-1950 (Baile Átha Cliath, 1952).

${ }^{7}$ Seosamh Ó Duibhginn, 'An chois leointe', Feasta (Iúil 1948), 3-4.

${ }^{8}$ Máirtín Ó Cadhain, An braon broghach (Baile Átha Cliath, 1948).

${ }^{9}$ Máirtín Ó Cadhain, Cois caoláire (Baile Átha Cliath: 1953).

${ }^{10}$ Alan Titley, Máirtín Ó Cadhain: clár saothair (Baile Átha Cliath, 1975), 49-51; An tSr Bosco Costigan \& Seán Ó Curraoin, De ghlaschloich an oileáin: beatha agus saothar Mháirtín Uí Chadhain (Béal an Daingin, 1987), 198-9.
} 
in Cois caoláire, ${ }^{11}$ agus an leagan a foilsíodh in Feasta Márta 1951. ${ }^{12}$ Níor mhór a chur san áireamh gur tréimhse dhian i saol Uí Chadhain na blianta iarchogaidh seo nuair nach raibh buanfhostaíocht aige ach é ag saothrú leis, ar nós Uí Dhuibhginn, ar thionscnaimh éagsúla go dtí gur ceapadh mar aistritheoir i Rannóg an Aistriúcháin ar 12 Márta 1947 é.

Tá tábhacht mar aon le tionchar na tréimhse a chaith Ó Cadhain sa champa géibhinn ar a fhorbairt mar scríbhneoir aitheanta ag criticeoirí éagsúla. Cé go maíonn Alan Titley gur sa bhearna idir Cois caoláire agus An tsraith ar lár (1967) is ea a 'dhein Máirtín Ó Cadhain scríbhneoir nua-aoiseach de féin', ${ }^{13}$ molann Gearóid Denvir 'an dáta sin a chur siar achar blianta agus saoire Uí Chadhain i Sibéir na hÉireann, Campa Géibhinn an Churraigh le linn an dara cogadh domhanda, a chur san áireamh'.$^{14}$ Luann Denvir na litreacha a scríobh Ó Cadhain chuig Tomás Bairéad mar léiriú ar an mborradh intleachtach a tháinig faoi sa tréimhse sin. Tá feasacht Uí Chadhain ar éifeacht a chuid léitheoireachta agus machnaimh ar a shaothar cruthaitheach soiléir ón méid seo a scríobh sé i litir chuig an mBairéadach ar 20 Aibreán 1944: 'An rud is measa fúm anois go bhfuil éascaíocht agus bisiúlacht smaointe ionam nach raibh ariamh cheana ... rinne an géibheann seo a lán cor in m'inntinn' ${ }^{15}$ Míníonn sé an treo atá faoina shaothar i litir eile chuig an mBairéadach ar 8 Bealtaine 1944, agus díol suntais gur i dtéarmaí seánra a thagraíonn sé do shaothair ghearrscéalaíochta áirithe a bhí ar na bacáin aige, saothair ar 'Úirscéalta gearra' i ndáiríre iad, dar leis. ${ }^{16}$ Luann sé 'An t-aonú fleasc déag', an scéal is faide in An braon broghach, mar cheann de na 'húirscéalta gearra' sin. Ardaíonn an scéal céanna ceisteanna faoin tréimhsiú a dhéantar ar shaothar Uí Chadhain ar bhonn foirme nó ábhair, sa mhéid, mar a deir Gearóid Denvir, gur 'sainscéal cathrach dá chuid é a bhfuil na tréithe ar fad ann a thiocfadh chun forbartha i scéalta cathrach na Sraitheanna éagsúla'. ${ }^{17}$ Is scéal é a sháraíonn teorainneacha an réalachais agus a bhfuil gné na haoire sóisialta go láidir ann, agus, i bhfocail Dhiarmada Uí Ghráinne, ba

\footnotetext{
${ }^{11}$ Máirtín Ó Cadhain, 'Glantachán earraigh', Irish Independent (23 Nollaig 1946); Cois caoláire (Baile Átha Cliath, 1953), 9-11.

${ }^{12}$ Máirtín Ó Cadhain, 'Glantachán earraigh', Feasta (Márta 1951), 8-9.

${ }^{13}$ Alan Titley, 'Ag déanamh páipéir - foinsí inspioráide an Chadhnaigh', in Eoghan Ó hAnluain (eag.), Léachtaí Uí Chadhain I (1980-1988) (Baile Átha Cliath, 1989), 39.

${ }^{14}$ Gearóid Denvir, 'Ó chill go cré', in Eoghan Ó hAnluain (eag.), Léachtai Uí Chadhain I (1980-1988) (Baile Átha Cliath, 1989), 140.

${ }^{15}$ Máirtín Ó Cadhain, As an ngéibheann: litreacha chuig Tomás Bairéad (Baile Átha Cliath: 1973), 141-2.

${ }^{16}$ Ibid., 144.

${ }^{17}$ Gearóid Denvir, Cadhan aonair: saothar liteartha Mháirtín Ui Chadhain (Baile Átha Cliath, 1987), 98.
} 
é an scéal seo 'an chéad iarracht ag an gCadhnach chun déileáil leis an gcoimhthíoch ar an bhfaraor géar ar shráideanna Bhaile Átha Cliath'. ${ }^{18}$ Is dóigh linn, más ea, go bhféadfaí breathnú ar shaothar cruthaitheach Uí Chadhain ó aimsir An braon broghach ar aghaidh mar léiriú ar phróiseas leanúnach chun teacht ar fhoirmeacha a bheadh oiriúnach dá fhís ealaíne. Is éard atá suntasach faoin litir atá faoi chaibidil againn anseo, áfach, ná go bhfuil cuid mhaith den chomhairle a chuireann Ó Cadhain ar Ó Duibhginn lonnaithe i gcomhthéacs tuiscintí a bhí coitianta ag an am ar fhoirm agus ar ealaín an ghearrscéil, tuiscintí ar féidir iad a rianú siar chuig Edgar Allan Poe, Chekhov agus cuid de ghearrscéalaithe móra na Fraince. Aithneofar gurb é an comhthéacs liteartha idirnáisiúnta céanna atá i gceist sna haistí ar an ngearrscéal a d'fhoilsigh Sean O'Faolain in The Bell idir Eanáir agus Iúil 1944. ${ }^{19}$ Craoladh aistí sin O'Faolain mar chainteanna raidió ar Raidió Éireann sa bhliain 1942 agus foilsíodh ina dhiaidh sin sa leabhar The short story iad. ${ }^{20}$ Chomh maith leis sin, mar a phléifear níos mine thíos, baintear earraíocht sa litir as téarmaí agus coincheapa léirmhínithe atá in úsáid ag Áine Ní Chnáimhín ina leabhar critice Pádraic Ó Conaire a foilsíodh níos déanaí sa bhliain 1947. Agus í ag trácht ar an gceardaíocht liteartha sa leabhar sin, luann Ní Chnáimhín an chaoi ar thug Ó Conaire cúl leis na seanmhodhanna scríofa agus ar 'chuir sé i bhfeidhm an t-eolas ar cheirdneacht na scéalaidheachta a d'fhoghluim sé ó cheárdaidhthe na Rúise, na Frainnce, Shasana agus Mheiriocá. ${ }^{21}$ Is cinnte go bhféadfaí an rud céanna a rá faoi Mháirtín Ó Cadhain, agus cuireann an litir seo lenár dtuiscint ar an gcomaoin a chuir smaointeoireacht liteartha a linne air. Is dóigh linn gur fíor, mar atá áitithe ag Alan Titley agus é ag trácht ar shaothrú an ghearrscéil ag an gCadhnach, gur 'thug sé lántsaoirse don tsamhlaíocht agus don neamhspleáchas ealaíne' agus gur 'chuir sé an fhoirm in oiriúint don scéal agus ní an scéal in oiriúint don fhoirm', ${ }^{22}$ agus gur 'ródhócha gur chuma leis

\footnotetext{
${ }^{18}$ Diarmaid Ó Gráinne, An dá Mháirtín (Baile Átha Cliath: Comhar Teo, 1990), 16.

${ }^{19}$ O'Faolain, Sean. 'The craft of the short story 1: When is a story not a story?', The Bell, vol.7, no.4 (Jan. 1944), 337-44; 2: 'Some essential conventions', The Bell, vol. 7, no.5 (Feb. 1944), 403-10; 3: 'Significant construction', The Bell, vol. 7, no.6 (Mar. 1944), 529-36; 4: 'Instead of plot', The Bell, vol. 8, no.1 (Apr. 1944), 46-54; 5: 'The problem of style', The Bell, vol. 8, no. 4 (July 1944), 306-14. Is cinnte go mbeadh aistí O'Faolain léite ag Ó Cadhain. Feic na tagairtí do na Bells a bheith á seoladh chuige agus é sa Churrach in As an ngéibheann, 57.

${ }^{20}$ Sean O'Faolain, The short story (London, 1948). Is d'eagrán Mercier, a foilsíodh sa bhliain 1972, a thagrófar thíos.

${ }^{21}$ Áine Ní Chnáimhín, Pádraic Ó Conaire (Baile Átha Cliath, 1947), 229.

${ }^{22}$ Alan Titley, 'Máirtín Ó Cadhain agus foirm an ghearrscéil', in Chun doirne: rogha aistí (Béal Feirste, 1996), 125. Céadfhoilsíodh in Comhar (Deireadh Fómhair 1980), 34-40.
} 
faoi na rialacha' ${ }^{23}$ Mar sin féin, níorbh ionann saoirse ealaíne agus ainriail i gcás shaothar cruthaitheach Uí Chadhain in am ar bith. Thar aon rud eile, b'fhéidir, léiríonn an litir phearsanta seo an dua agus an dúthracht a chaith Ó Cadhain le ceird na scríbhneoireachta, agus an cur chuige tomhaiste loighciúil anailíseach a chleacht sé agus é ag cur síos uirthi.

\section{An comhthéacs liteartha agus soch-chultúrtha}

Tá sé le cur san áireamh go raibh nualitríocht na Gaeilge lagmheanmnach go leor ag deireadh na ndaichidí, agus gur braitheadh go raibh gá le spreagadh agus le tacaíocht má bhí rath le teacht uirthi. ${ }^{24}$ Bhí an Comhchaidreamh, a bunaíodh sa bhliain 1935, mar ghréasán tábhachtach sóisialta agus gairmiúil do chéimithe agus d'fhochéimithe ollscoile ${ }^{25}$ agus bhí Cumann na Scríbhneoirí ag feidhmiú mar láthair plé agus díospóireachta san ardchathair ón mbliain 1939 ar aghaidh. ${ }^{26}$ Cé go raibh baint ag príomhscríbhneoirí Gaeilge na linne le Cumann na Scríbhneoirí ag an am - Máirtín Ó Direáin, Séamus Ó Néill, Máiréad Ní Ghráda, Annraoi Ó Liatháin, L.S. Gógan agus Máirtín Ó Cadhain féin ina measc - ní mórán measa a bhí ag Ó Duibhginn ar imeachtaí an Chumainn ná ar ghluaiseacht na Gaeilge i gcoitinne sna daichidí:

Níor bhac mé mórán san am sin le imeachtaí oifigiúla Ghluaiseacht na Gaeilge. Conlán nó coterie diliteantach, a raibh mórtas tónach ag roinnt leo, a bhí iontu, chonacthas dom. Thug mé síntiús do Chumann na Scríbhneoirí agus théinn chuig a gcuid cruinniú in Óstán Uí Eidhin ó am go ham. Ní bhíodh ann ach triúr nó ceathrar ban agus dosaen fear nó mar sin agus a mbunáite feosaí liath as a n-aghaidh. Shuídís thart ag baint súimíní as deochanna beaga biotáille agus giorrú cainte ar siúl acu. $^{27}$

B'fhéidir gur léiriú ar a chlaonadh nádúrtha i dtreo na hiriseoireachta seachas i dtreo na litríochta cruthaithí atá i gceist nuair a tharraingíonn sé aird chriticiúil ar a laghad suime a chuir

\footnotetext{
${ }^{23}$ Alan Titley, Scríbhneoirí faoi chaibidil (Baile Átha Cliath, 2010), 15.

${ }^{24}$ Féach ar an bplé ar an ábhar seo in Aisling Ní Dhonnchadha, Idir dhúchas agus dualgas: staidéar ar charachtair mhná sa ghearrscéal Gaeilge 1940-1990 (Baile Átha Cliath, 2002), 233-37.

${ }^{25}$ Stiofán Ó hAnnracháin (eag.), An Comhchaidreamh: crann a chraobhaigh (Baile Átha Cliath, 1985).

${ }^{26}$ Máirín Ní Mhuiríosa, 'Cumann na scríbhneoirí - memoir', Scriobh 5 (1981), $168-81$.

${ }^{27}$ Ó Duibhginn, Ag scaoileadh sceoil, 114.
} 
comhaltaí an Chumainn i gceisteanna polaitíochta agus sóisialta. Ina ionad sin, a deir sé, is ag plé foirmeacha litríochta a bhídís agus ag gearán faoi mhóreasnaimh an Ghúim:

Suim dá laghad níor chuir comhaltaí an Chumainn sna ceisteanna móra sóisialachais agus comhdhaonnachta a raibh an domhan suaite acu, nó má chuir níor lig siad a rún le aon duine. Foirmeacha liteartha, go háirithe an ghearrscéalaíocht agus filíocht an ochtú céad déag, is mó bhíodh faoi thrácht acu, maraon le corrshiolla faoin drámaíocht. Cés moite de na hábhair sin bhí An Gúm acu. B'é an Gúm an namhaid ba mhó a bhí acu. De shíor bhídís ag tromaíocht air. Brainse den Státseirbhís bhí san Ghúm agus níor cheart foilsiú leabhar a fhágáil faoin Státseirbhís. Ach ní raibh foilsitheoirí eile toilteanach leabhair Ghaeilge a fhoilsiú. Níor chuimhnigh siad riamh ar éigeandáil an chogaidh. Thráchtadh siad ar shaoirse na litríochta agus ar shaoirse scríbhneoirí amhail is dá mbeadh a gcuid pócaí ag cur thar maol le saothar cruthaíoch réabhlóideach nach ndrannfadh córas coimeádach státseirbhíseach leis. Bhunaigh siad a n-éileamh agus a n-argóint ar 'cheist' na Gaeilge féin agus ní ar an scríbhneoireacht per $s^{28} .^{28}$

Bhí iarrachtaí ar siúl láithreacha foilsitheoireachta a chur ar fáil do scríbhneoirí Gaeilge ag an am. Bhí na hirisí liteartha Comhar (a bhunaigh an Comhchaidreamh sa bhliain 1942) agus Feasta (iris liteartha Chonradh na Gaeilge a tháinig i gcomharbacht ar $A n$ Glór [1941-1948] in Aibreán 1948), chomh maith leis an nuachtán seachtainiúil Inпiu (1943-1984) agus irisí cúigeacha mar Ar Aghaidh (1931-1970), ag soláthar ardán don nuachumadóireacht agus don chritic araon. Chomh maith leis sin, bhí ábhar Gaeilge á fhoilsiú go rialta san Irish Independent agus i Scéala Éireann.

Ba é bunú an chomhlachta Sáirséal agus Dill ag Seán Sáirséal Ó hÉigeartaigh sa bhliain 1947 an rud ba thábhachtaí a tharla ó thaobh na foilsitheoireachta Gaeilge de sna daichidí. D'fhoilsigh Sáirséal agus Dill a gcéad saothar sa bhliain sin, an t-úrscéal Tonn tuile le Séamus Ó Néill. ${ }^{29}$ Chuidigh bunú an Chlub Leabhar sa bhliain 1948 le feabhas a chur ar chúrsaí díolaíochta agus cuireadh taca nua stáit ar fáil d'fhoilsitheoireacht na Gaeilge le bunú Bhord na Leabhar Gaeilge sa bhliain 1952. Níl amhras ar bith ach go raibh údar frustrachais agus éadóchais ag scríbhneoirí Gaeilge sa tréimhse

\footnotetext{
${ }^{28}$ Ibid., 115.

${ }^{29}$ Séamus Ó Néill, Tonn tuile (Baile Átha Cliath, 1947).
} 
iarchogaidh, áfach, agus léirítear cuid mhaith den fhrustrachas sin sa léacht cháiliúil ‘Tuige nach bhfuil litríocht na Gaeilge ag fás?’ a thug Máirtín Ó Cadhain don Chumann Liteartha sa Choláiste Ollscoile, Baile Átha Cliath sa bhliain 1949, áit ar chuir sé an cheist: 'Tuige ... nach bhfuil oidhrí i bhfarradh an Phiarsaigh, Uí Chonaire agus Mhic Grianna?'. ${ }^{30} \mathrm{Ar}$ cheann de na cúiseanna a luann Ó Cadhain sa léacht, tá an 'easpa léirmheastóireachta tuisceanaí':

Ceann de na rudaí is mó atá ag cur isteach ar litríocht na Gaeilge is easpa léirmheastóireachta tuisceanaí é. Ba chóir dar ndóigh, go mba é léirmheas an scríbhneora féin ar a shaothar féin an léirmheas ba ghéire ar fad sa deireadh. Ach is deacair don scríbhneoir a bheith amhlaidh go ndéantar measadh tuisceanach air féin nó ar dhaoine eile atá ag scríobh in aon teanga leis. D'ainneoin go bhfuil rí-shaothar déanta ag Domhnall Ó Corcora i dtaobh gnéithe áirithe de litríocht na Gaeilge, agus gur scríobh Seosamh Mac Grianna aistí breá, go háirithe an ceann faoi Phádraic Ó Conaire, is féidir a rá sílim nach bhfuil aon léirmheastóireacht ar litríocht an lae inniu. ${ }^{31}$

Ba bhreithiúnas pas géar é seo ar na hiarrachtaí léirmheastóireachta a rinneadh sa tréimhse tar éis bhunú an stáit. Iarracht thomhaiste ar cháilíochtaí na litríochta agus ar theoiricí na nua-sheánraí a mhíniú a bhí i leabhar an Athar Seoirse Mac Clúin An litríocht: infhiúcha ar phrionnsabail, fuirmeacha agus léirmheastóireacht na litríochta (g.d. [1926]), saothar a bhí bunaithe ar léitheoireacht fhairsing ar litríocht an Iarthair ach a thagair freisin do shaothair le scríbhneoirí Gaeilge mar Ó Grianna, an tAthair Peadar Ua Laoghaire agus an Piarsach. ${ }^{32} \mathrm{Ba}$ iarrachtaí fónta tús a chur le plé tuisceanach ar litríocht na linne na téacsleabhair Litríocht na Gaedhilge (1929) agus An léirmheastóir (1931), le Críostóir Ó Raghallaigh..$^{33}$ Díolaim agus téacsleabhar léirmhínithe iad seo arbh iad saothair na n-údar comhaimseartha Gaeilge (pléitear saothar le seachtar déag in $A n$ léirmheastóir) a bhí á léiriú agus á gcíoradh iontu. Scagadh ar shaothair chomhaimseartha a bhí ar siúl ag Séamus Ó Searcaigh freisin ina leabhar Nua-sgríbhneoirí na Gaedhilge (1931), fiú más

\footnotetext{
${ }^{30}$ Máirtín Ó Cadhain, 'Tuige nach bhfuil litríocht na Gaeilge ag fás?' in Seán Ó Laighin (eag.), Ó Cadhain i bhFeasta (Baile Átha Cliath, 1990), 86. Céadfhoilsíodh in Feasta (Samhain 1949).

${ }^{31}$ Ibid., 92.

${ }^{32}$ Mac Clúin, Seoirse, An litríocht: infhiúcha ar phrionnsabail, fuirmeacha agus léirmheastóireacht na litríochta (Baile Âtha Cliath, g.d. [1926]).

${ }^{33}$ Críostóir Ó Raghallaigh, Litríocht na Gaedhilge (Baile Átha Cliath, 1929); An léirmheastóir (Baile Átha Cliath, 1931).
} 
eolas faoi na húdair agus cuntas tuarascálach ar a saothar seachas anailís ghrinn liteartha is mó atá le fáil ann. ${ }^{34} \mathrm{D}$ 'fhéadfaí a áiteamh go raibh feidhm leis an gcur chuige tuarascálach sin ag an am, agus go raibh tábhacht ar leith le saothair thagartha mar Taighde i gcomhair stair litridheachta na Nua-Ghaedhilge ó 1882 anuas (1936) le Muiris Ó Droighneáin, áit a rianaítear comharthaí sóirt litríocht na tréimhse. ${ }^{35}$ Tá léirmheastóireacht na dtríochaidí ina scáthán ar an éagsúlacht idé-eolaíochta agus tuairimíochta a bhí i réim ag an am, ó thraidisiúnachas duine mar Shán Ó Cuív, údar Prós na haoise seo (1933), ${ }^{36}$ ar mhó a spéis i gcáilíochtaí teanga saothar ná i ngné ar bith eile den insint, go dtí iarracht chomhfhiosach Liam Uí Rinn dearcadh liteartha níos iltírí a shaothrú ina ailt irise agus ina leabhar neamhchoitianta dírbheathaisnéise, Mo chara Stiofán (1939). ${ }^{37}$ Agus é ag trácht ar litríocht dhioscúrsúil na Gaeilge sna tríochaidí agus sna daichidí, aithníonn Gearóid Denvir nár mhiste 'a áiteamh gur sa chuid is fearr de na leabhair seo atá tús na critice sa Ghaeilge le fáil' ${ }^{38}$ Aithnítear an ghné láidir theagascach i gcuid de na saothair, mar gur tuigeadh do na húdair gur ghá an pobal a threorú agus ábhair scríbhneora a ghríosadh. Leabhar teagascach is ea an leabhar Peann agus pár (1940) le Ó Rinn, ${ }^{39}$ mar shampla, bunaithe ar aistí iriseoireachta leis féin, ach é múnlaithe ar a mhacasamhail de threoirleabhair i mBéarla (luann sé na leabhair: The lure of the pen le Flora Klickmann; The technique of novel writing le Basil Hogarth; agus dhá leabhar le Michael Joseph, Short story writing for profit agus How to write a short story).$^{40}$ Níorbh é Ó Rinn an t-aon scríbhneoir a ghlac cúram an chomhairleora air féin sa tréimhse seo; liostaíonn Philip O'Leary sraitheanna d'aistí comhairleacha a d'fhoilsigh údair éagsúla sna tréimhseacháin Ghaeilge idir lár agus deireadh na ndaichidí, ina measc sraitheanna le Ciarán Ó Nualláin, Séamus Ó Néill, agus Tarlach Ó hUid. ${ }^{41}$

Is díol suime gurb é an scríbhneoir cruthaitheach Seosamh Mac Grianna, údar Pádraic Ó Conaire agus aistí eile (1936), ${ }^{42}$ an t-aon

\footnotetext{
${ }^{34}$ Séamus Ó Searcaigh, Nua-sgríbhneoirí na Gaedhilge (Baile Átha Cliath, 1931).

${ }^{35}$ Muiris Ó Droighneáin, Taighde i gcomhair stair litridheachta na Nua-Ghaedhilge ó 1882 anuas (Baile Átha Cliath, 1936).

${ }^{36}$ Shán Ó Cuív, Prós na haoise seo (Baile Átha Cliath, 1933).

${ }^{37}$ Liam Ó Rinn, Mo chara Stiofán (Baile Átha Cliath, 1939).

${ }^{38}$ Gearóid Denvir, 'Ó shíolteagasc go critic: litríocht dhioscúrsúil na Gaeilge san aois seo', in Ruairí Ó hUiginn (eag.), Léachtai Cholm Cille 26: Léann na Gaeilge (Maigh Nuad, 1996), 198.

${ }^{39}$ Liam Ó Rinn, Peann agus pár (Baile Átha Cliath, 1940).

${ }^{40}$ Ibid., 15

${ }^{41}$ Philip O'Leary, Writing beyond the revival: facing the future in Gaelic prose (Dublin, 2011), 442-3.

${ }^{42}$ Seosamh Mac Grianna, Pádraic Ó Conaire agus aistí eile (Baile Átha Cliath,
} 
údar a dtugann Ó Cadhain aitheantas dó mar léirmheastóir ina léacht 'Tuige nach bhfuil litríocht na Gaeilge ag fás?'. Mar atá áitithe ag Gearóid Denvir, 'cloch mhíle thábhachtach i bhforbairt na litríochta dioscúrsúla sa Ghaeilge'43 a bhí i leabhar seo Mhic Grianna, comhartha aitheantais do shárscríbhneoir ghluaiseacht liteartha na hAthbheochana ó mhórscríbhneoir Gaeltachta comhaimseartha. Tá sé le brath go láidir ar théacs na litreach atá á foilsiú againn anseo go raibh an t-ionad a bhí dlite dó féin i saol liteartha a linne ar chúl a intinne ag Ó Cadhain agus é á scríobh. Braitear guth teanntásach an údair a chreideann ina chumas féin ar thuin na litreach agus ar údarás na mbreithiúnas a dhéantar inti. Cáintear saothar Shéamuis Uí Ghrianna, an t-údar Gaeltachta ba mhó a bhí i mbéal an phobail ag an am, agus nochtar na tuairimí láidre céanna faoi chur chuige foirmleach Uí Ghrianna a nochtfaí arís i bhfoilseacháin eile níos déanaí. ${ }^{44}$

\section{Ó Cadhain mar chomhairleoir agus mar ghrinnléitheoir}

Is iad na gnéithe is inspéise den litir seo na pointí stíle a ndíríonn Ó Cadhain a aird go sonrach orthu agus na tagairtí a dhéanann sé dá shaothar féin agus pointí á gcur abhaile ar Ó Duibhginn aige. Cé go bhfuil sé diongbháilte mar chomhairleoir, ní léir i gcónaí gurb é a chleachtas cruthaitheach féin an léiriú is fearr ar a chuid teagaisc agus teoiricíochta. Maidir le teidil scéalta, mar shampla, molann sé don Duibhginneach gan an iomarca eolais a scaoileadh uaidh i dteideal a scéil ach ag an am céanna gan an teideal a bheith rótheibí ná do-thuigthe: 'Rud eile faoi thiodail ná bídís do-thuigthe fearacht An braon broghach mar ainm leabhair agamsa'. Gan dabht, is léir gur theastaigh ón gCadhnach dul traidisiúnta theideal a chéad chnuasaigh, Idir shúgradh agus dáirire, a sheachaint nuair a roghnaigh sé teideal meafarach don dara cnuasach scéalta a foilsíodh sa bhliain $1948{ }^{45}$ D'admhaigh léirmheastóir amháin, Seán Ó Catháin, in The Irish Monthly, Bealtaine $1949,{ }^{46}$ nár thuig sé cad ba bhrí le teideal an

1936). Is d'eagrán 1969 den leabhar a thagrófar thíos.

${ }^{43}$ Denvir, 'Ó shíolteagasc go critic', 197.

${ }^{44}$ Máirtín Ó Cadhain, Léirmheas ar An teach nár tógadh le Séamus Ó Grianna, Ar Aghaidh (Márta 1949), foilsithe faoin ainm cleite D. Ó Gallchobhair, agus athfhoilsithe in An tSr. Boscó Costigan, Seán Ó Curraoin, De ghlaschloich an oileáin (Indreabhán, 1987), 345-7; 'Páipéir bhána agus páipéir bhreaca' (Baile Átha Cliath, 1969), 19-20.

${ }^{45}$ Maidir le dul traidisiúnta theidil scéalta an chnuasaigh Idir shúgradh agus dáiríre, feic a ndeir Flann Mac an tSaoir, 'Máirtín Ó Cadhain', Comhar (Bealtaine 1952), 28; agus Nollaig Mac Congáil, 'Teideal an ghearrscéil sa Ghaeilge', Comhar (Eanáir 1975), 20-1.

${ }^{46}$ Seán Ó Catháin, Léirmheas ar An braon broghach, The Irish Monthly (Bealtaine 1949), 244. 
dara cnuasach sin, An braon broghach. Tuigtear don chriticeoir Philip O’Leary go bhfeidhmíonn an teideal mar léiriú comhfhiosach Uí Chadhain ar an gcor nua cruthaitheach a bhí á thabhairt ag a shaothar sa tréimhse áirithe sin:

As he himself knew full well, Idir Shúgradh agus Dáiríre, while at its best up to the standard of the finest fiction produced by the revival to that time, was for him apprentice work, a fact he acknowledged by titling his second collection An Braon Broghach, 'the dirty drop', a reference to the first drippings from a poitin still before the good stuff starts to flow. For him, this second collection marked the beginning of his mature literary output, the first samples of the extraordinary outpouring that would change Gaelic prose forever. ${ }^{47}$

Faightear spléachadh eile ar an tábhacht a shamhlaigh Ó Cadhain le teideal gearrscéil i litir eile (gan dáta) a sheol sé chuig Ó Duibhginn tamall i ndiaidh na litreach atá faoi chaibidil anseo againn. Thrácht sé go mion arís sa dara litir ar theideal agus ar ábhar a ghearrscéil, 'Glantachán earraigh', ar bhealach a léiríonn go raibh an Duibhginneach i ndiaidh Ó Cadhain a cheistiú i dtaobh oiriúnacht theideal an scéil sin, a foilsíodh san Irish Independent ar 23 Nollaig 1946. Is léir ó fhreagra an Chadhnaigh ar an gceist sin nach raibh sé sásta leis an leasú teidil ná na fotheidil a cuireadh i bhfeidhm ar leagan foilsithe a scéil, pointí ar thagair sé dóibh roimhe sin sa chéad litir.

Agus é ag trácht sa dara litir ar an tslí ar milleadh an scéal, dar leis, déanann sé idirdhealú soiléir idir foirm an ghearrscéil agus leagan amach an cholúin iriseoireachta:

Len a athrá ní dréacht columnist a bhí ann. Rinne an t-eagarthóir sin dhe len a chuid tiodal, ach níorbh ea mar sin fhéin ... Sén tiodal ceart é 'Glantachán Earraigh' (chuir an fear eagair tuilleadh leis agus mhill sé é mar nár thuig sé é ach oiread). ${ }^{48}$

\footnotetext{
${ }^{47}$ Philip O'Leary, Irish interior: keeping faith with the past in Gaelic prose 19401951 (Dublin, 2010), 396.

${ }^{48}$ Páipéir Uí Dhuibhginn, P172/378, Cartlann an Choláiste Ollscoile, Baile Átha Cliath.
} 


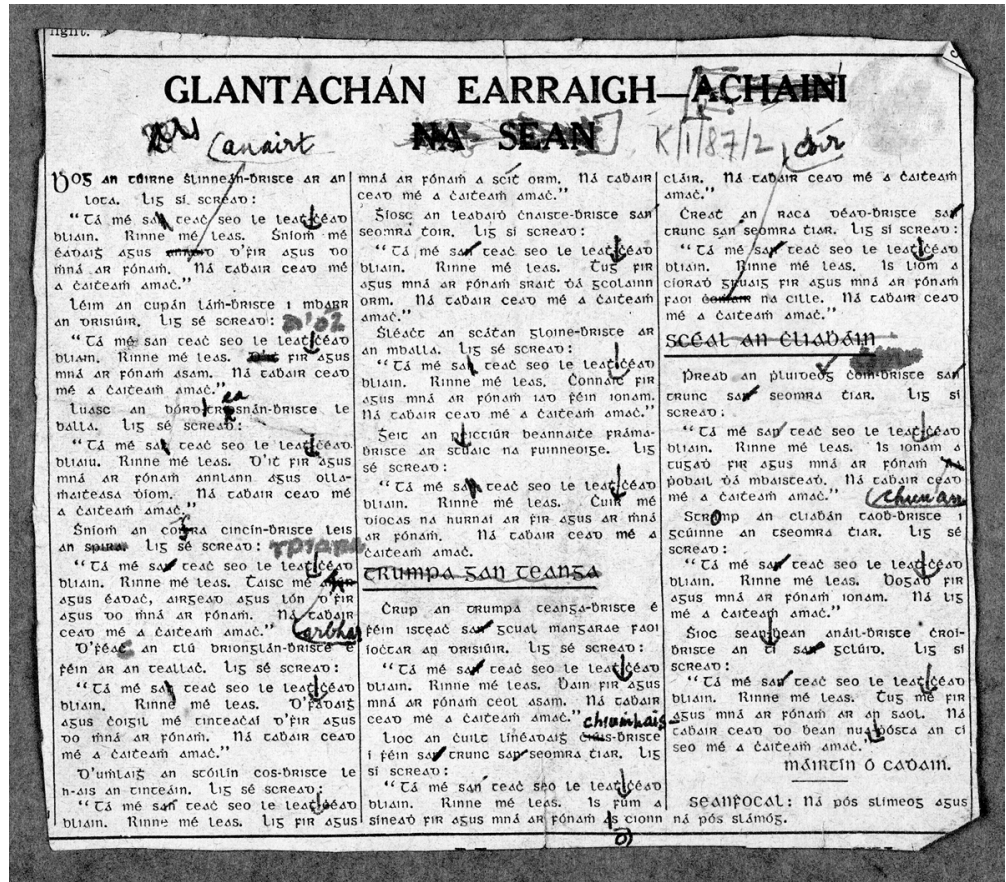

Cóip Mháirtín Uí Chadhain den scéal 'Glantachán Earraigh' as an Irish Independent, 23 Nollaig $1946^{49}$

Is maith le Ó Cadhain gur sheachain Ó Duibhginn an chríoch chleasach agus comhairlíonn dó gan aithris a dhéanamh ar stíl $\mathrm{O}$. Henry ná Maupassant: '... má chaitheann tú do scéal a chríochnú le cleas millfidh sé do chuid characterisation'. ${ }^{50}$ Is cinnte nár cheil Ó Cadhain a dhrochmheas ar O. Henry riamh, go háirithe agus é ag tagairt do thionchar O. Henry ar nua-scríbhneoireacht na Gaeilge. Sa léacht 'Tuige nach bhfuil litríocht na Gaeilge ag fás?', mar shampla, bhí an méid seo le rá aige:

${ }^{49}$ TCD Archives MS 10878/K/1/87/2. Foilsithe le caoinchead Chartlann Choláiste na Tríonóide.

${ }^{50}$ Is le O. Henry, ainm cleite an scríbhneora Mheiriceánaigh William Sydney Porter (1862-1910), is mó a shamhlaítear an chríoch chleasach mar chiúta stíle sa ghearrscéal. Tá 'The gift of the Magi' ar an ngearrscéal is cáiliúla leis ina n-úsáidtear an chríoch chleasach. Foilsíodh leagan Gaeilge den scéal sin sa chnuasach gearrscéalta Rogha na gConnachtach: cnuasacht gearr-sgéal (Baile Átha Cliath, 1937). 'Bronntanas na nDraoithe' an teideal a tugadh air agus ba é Pádraig Ó Moghráin a d'aistrigh go Gaeilge. 
Ar an gcuid is measa de ghearrscéalaithe an Bhéarla - O. Henry agus a leithéid - a níos an mhórchuid de na scríbhneoirí Gaeilge aithris. Dúirt an Piarsach nárbh fhéidir leabhar ar bith d'fhilíocht an Celtic Twilight a oscailt gan scuaine d'éanlaigh Aengusa a theacht ag eiteall as amach. Gearrcaigh O. Henry a thig as leabhra Gaeilge an lae inniu. ${ }^{51}$

Trí mhí sular foilsíodh an léacht sin in Feasta, foilsíodh léirmheas le Criostóir Mac Aonghusa ar Ór na haitinne, cnuasach gearrscéalta le Tomás Bairéad, ina ndúirt sé gur chleacht an Bairéadach 'insean à la O. Henry'. Lean Mac Aonghusa air:

... mar cumadh an múnla seo in aon turas le sásamh agus siamsa a thiúirt do dhaoine a bhfuil a gcuid lioganna céasta ag rí-rá agus ruaille-buaille an bhaile mhóir. Sin é an fáth a bhfuil oiread tóra orthu agus atá. Scríobhann Béarlóirí na táinte acu chuile bhliain agus tá irisleabhair Shasana agus Mheriocá ag cur thar maoil leo. Scríobhann na Gaeilgeoirí freisin iad. Go deimhin, níl scríbhneoir Gaeilge (ach beirt) ann faoi láthair nach féidir a áireamh i measc sliocht $\mathrm{O}$. Henry. ${ }^{52}$

Níor mhiste cíoradh breise a dhéanamh ar chuid den tuairimíocht seo faoi thionchar O. Henry, áfach. Cé gur dhamnaigh O'Faolain O. Henry de bharr 'commercial stories' a scríobh, ${ }^{53}$ is cinnte go raibh an-éileamh go deo ar scéalta an scríbhneora Mheiriceánaigh seo agus ar an seánra áirithe sin trí chéile. Sa réamhrá a chuir John Hadfield leis an gcnuasach Modern short stories (1939), thagair sé don ráchairt mhór a bhí tagtha ar scéalta irise agus nuachtáin ó dheireadh an naoú céad déag amach agus is go dearfach ómósach a thrácht sé ar shaothar $\mathrm{O}$. Henry agus ar an scil a léirigh sé i dtaca le 'the tale with an unexpected ending'. ${ }^{54}$ Tugaimid faoi deara gur mhol Mac Clúin an ghné seo de theicníc scéalaíochta O. Henry, is é sin, a inniúla a bhí sé ar fhiosracht agus spéis an léitheora a mhúscailt agus a choimeád go dtí críoch an scéil: 'Ansan amháin a thagann an foillsiú, an nochta, an poinnte gur deineadh an cóiriú go léir chuige. ${ }^{55}$ I dtuairim H.E. Bates, sháraigh ceardaíocht $\mathrm{O}$. Henry scil scéalaíochta scríbhneoirí

${ }^{51}$ Máirtín Ó Cadhain, ‘Tuige nach bhfuil litríocht na Gaeilge ag fás?’, 93.

${ }^{52}$ Criostóir Mac Aonghusa, Léirmheas ar Ór na haitinne le Tomás Bairéad, Feasta (Lúnasa 1949), 16-17.

${ }^{53} \mathrm{O}$ 'Faolain, 'The craft of the short story 1: When is a story not a story?', The Bell, vol.7, no.4 (Jan. 1944), 337; feic freisin The short story (Cork, 1972), 204.

${ }^{54}$ John Hadfield, Modern short stories (London, 1939), viii, x.

${ }^{55}$ Mac Clúin, An litríocht, 192. 
eile a bhain leas as an gcríoch chleasach roimhe: 'But for some reason O. Henry's use of it captures the imagination not only of readers but also of writers ... ${ }^{56}$ Ar ndóigh, aithníonn léitheoirí nach 'críoch chleasach' a bhíonn i gceist i gcónaí ag scríbhneoirí éagsúla a fhéachann le haidhm nó le 'fírinne' an scéil a nochtadh i gclabhsúr a gcuid scéalta. Faoi mar a shonraíonn Ian Reid:

$\ldots$ an excessive emphasis on ingenious plotting ... and especially a relish for the Final Twist as exemplified most notoriously in the writings of $\mathrm{O}$. Henry, is particularly unfortunate since it has tended to provoke a reactive critical disparagement of all surprise endings, some of which are however not manipulative devices but ways of elucidating meanings latent in the whole narrative. ${ }^{57}$

Nach bhféadfaí a rá gurb é sin go díreach an múnlú scéil a bhí i gceist i gcríoch 'Glantachán earraigh', mar shampla, críoch a sholáthraíonn léargas ar an bpríomhthéama a bhí á fhorbairt céim ar chéim sa scéal suas go dtí an pointe deiridh sin?

I gcomhthéacs ealaín na scríbhneoireachta cruthaithí, ní deacair dúinn col an Chadhnaigh le scéalta foirmleacha O. Henry a thuiscint, scéalta éadroma soléite a raibh "shades and subtleties" ${ }^{58}$ mar aon le doimhneacht bhraistinte agus spéisiúlacht aeistéitiúil in easnamh orthu. San anailís scolártha a dhéanann Heather Ingman ar shaothar ghearrscéalaithe Béarla na hÉireann sna 1940í agus na 1950í, tarraingíonn sí aird an léitheora ar ghné phraiticiúil de shaol an scríbhneora sa tréimhse úd nuair a bhíothas ag brath, cuid mhaith, ar fhoilsitheoirí lasmuigh d'Éirinn. Tráchtann sí ar an New Yorker, iris liteartha inar foilsíodh gearrscéalta le scríbhneoirí Éireannacha ar nós Frank O’Connor, Brian Friel agus Mary Lavin agus, níos déanaí, Edna O'Brien, Benedict Kiely agus William Trevor, agus músclaíonn sí ceist shuimiúil faoi chleachtadh an ghearrscéil (agus tionchar O. Henry san áireamh) sa tréimhse sin:

The number of Irish writers published with the magazine raises the question of the extent to which the editorial policies of the New Yorker affected the shape of the Irish short story during this period ... The word limit was restricting for authors, obliging

\footnotetext{
${ }^{56}$ H.E. Bates, The modern short story: a critical survey (London, 1941), 61.

${ }^{57}$ Ian Reid, The short story (London, 1977), 60.

${ }^{58} \mathrm{O}$ 'Faolain, 'The craft of the short story 1', 343.
} 
them to concentrate on setting, mood and character rather than plot: the fiction editor, Katherine White, disliked plot and wished to distance the New Yorker from the surprise endings of the still popular O. Henry stories. There had to be a fair amount of dialogue and the preferred tone was understated irony with few flights of fancy or displays of emotion. ${ }^{59}$

Níl amhras ar bith ach go raibh an Cadhnach faoi thionchar na teoiricíochta a bhí ag teacht chun cinn ag an am nuair a thrácht sé ar an ngearrscéal mar "an dréacht nach mbíonn "scéal" ar bith ann ar an tsean-chaoi'. Glacaimid leis gur ag tagairt a bhí sé anseo do dhul ar gcúl stíl thraidisiúnta reacaireachta, mar a mbíodh an bhéim ar chúrsaí plota agus eachtraíochta. Faoi mar a scríobh O'Faolain in The Bell trí bliana roimhe sin:

If we examine some of the best stories of modern times in order to distinguish the essential and more valuable elements from the accidental and less valuable elements, I think that we must find that the least essential element of all is the actual 'story' or anecdote itself. The anecdote is, rather, the enemy of the writer of stories. ${ }^{60}$

Dar le O'Faolain níorbh fholáir don ghearrscéal nua-aimseartha 'subtle comment on human nature ${ }^{61}$ a chur in iúl chomh maith. Nuair a chomhairligh Ó Cadhain don Duibhginneach an tseanmóireacht a sheachaint, gan a thuairimí féin a nochtadh toisc gur scríbhneoir seachas 'moralist'é, agus gan a raibh in intinn na gcarachtar a mhíniú sa ghearrscéal ach an méid sin a fhágáil faoin léitheoir féin, is féidir macallaí thráchtaireacht criticeoirí comhaimseartha ar nós H.E. Bates agus Sean O'Faolain a chloisteáil, a leithéidí seo, mar shampla: 'It is no longer necessary to describe; it is enough to suggest' ${ }^{62} ;$ nó '... a short story writer does not directly tell us things so much as let us guess or know them by implying them' ${ }^{\text {'3 }}$; nó 'He makes no moral observation; he leaves that to us'. ${ }^{64}$

Luann Ó Cadhain an tábhacht a shamhlaítear go coitianta le 'gach rud a thoghadh thar cionn' ionas nach mbeidh tada sa scéal ach a bhfuil

${ }^{59}$ Heather Ingman, A history of the Irish short story (New York, 2009), 158-9.

${ }^{60} \mathrm{O}$ 'Faolain, 'The craft of the short story 1', 337.

${ }^{61}$ Ibid., 338.

${ }^{62}$ Bates, The modern short story, 24.

${ }^{63} \mathrm{O}$ 'Faolain, 'The craft of the short story 2: Some essential conventions', The Bell, vol.7, no.5 (Feb. 1944), 405.

${ }^{64}$ O'Faolain, 'The craft of the short story 4: Instead of plot', The Bell, vol.8, no.1 (Apr. 1944), 54. 
ag teastáil. Bhí an ghné scríbhneoireachta seo, a luaitear de ghnáth i gcomhthéacs thionchar teoiricí Edgar Allan Poe, ar na saintréithe ba mhinice a luaití leis an ngearrscéal ó dheireadh an naoú haois déag go dtí lár an fichiú haois, agus, ní nach ionadh, chítear an cur chuige áirithe sin á phlé i saothair chritice na Gaeilge chomh maith. Mar shampla, thrácht Seoirse Mac Clúin ar dhúshlán choincheap sin na haontachta sa ghearrscéal in An litríocht ${ }^{65}$ agus leag Liam Ó Rinn béim ar thábhacht ghné na hiomláine ealaíonta sa ghearrscéalaíocht, in Peann agus pár. ${ }^{66}$ Cuimhnímis ar an méid a scríobh Seosamh Mac Grianna faoin ngearrscéal mar fhoirm liteartha sa bhliain 1936:

Ní bhaineann scéal gairid ach leis an aon eachtra amháin; ach caithfidh an eachtra a bheith filiúnta agus brí a bheith léi a mbeidh doimhne an tsaoil inti. Le fiche focal a chur in aon fhocal amháin, is cosúla scéal gairid le dán filíochta ná le cruth ar bith eile litríochta. Bogann sé an croí agus an intinn ar an dóigh chéanna a mbogann dán iad. Dálta an dáin, níl bun cleite amach nó barr cleite isteach ann. ${ }^{67}$

Léirigh Áine Ní Chnáimhín dílseacht mheoin i leith choincheap na haontachta mar bhuntréith stíle sa ghearrscéal clasaiceach ina saothar critice ar Ó Conaire. Chítear go ndearbhaíonn sí gurb í an aontacht 'an tréith is treise ar fad' de thréithe na gearrscéalaíochta agus luann sí an tábhacht shuaithinseach a ghabhann leis an 'aontacht chorruighthe agus mhothuighthe' sa ghearrscéal, leis:

Tá a leithéid d'aontacht i scéaltaibh Poe, Hawthorne, Maupassant, Daudet, Coppée agus Kipling. Chun an aontacht so d'aimsiughadh ní mór do'n ughdar gach cor a bhaineann leis an eachtra do chinneadh agus gach cuid de a chíoradh dhó féin sar a dtugann sé fé'n scéala do scríobhadh. Ní foláir dó ceirdneacht a bhíonn i n-oireamhaint do'n chorruighe a chur i bhfeidhm chun go mbeidh gach uile ghné de'n scéal - eachtra, pearsanradh, gníomhrughadh, suidheamh agus dath an scéil - fighte, fuaighte, fuinte i n-aon tsár-iomlán amháin. ${ }^{68}$

'Sé an comhrádh an rud is cumasaí a léiríos méin agus cáilíocht daoine', a deir Ó Cadhain sa litir. Gan amhras, léiríodh a shárchumas

${ }^{65}$ Mac Clúin, An litríocht, 187.

${ }^{66}$ Ó Rinn, Peann agus pár, 191-2.

${ }^{67}$ Mac Grianna, Pádraic Ó Conaire agus aistí eile, 29.

${ }^{68}$ Ní Chnáimhín, Pádraic Ó Conaire, 252-3. 
géarchúiseach féin nuair a bhí idir líofacht agus rithim réimeanna ilghnéitheacha comhrá á n-ionramháil aige i ngearrscéalta mar 'Fios', 'An pionta', 'An seanfhear', 'Smál', 'An t-othar', scéalta a craoladh ar Raidió Éireann le linn na bliana 1947. Craoladh 'An pionta' ar an 8ú lá de mhí Eanáir 1947, dhá lá tar éis do Ó Cadhain an litir seo chuig Ó Duibhginn a scríobh, agus foilsíodh cuid de na gearrscéalta sin in Feasta idir 1948 agus 1951 sular foilsíodh sa chnuasach Cois caoláire iad. ${ }^{69}$

Tugtar faoi deara sa phlé a dhéanann Ó Cadhain ar an tábhacht a bhaineann leis an gcur chuige tomhaiste cáiréiseach go ndeir sé le hÓ Duibhginn gur 'overtones' seachas 'undertones' a bhíonn le tabhairt faoi deara in an-chuid gearrscéalta Gaeilge, rud a laghdaíonn ar rannpháirtíocht ghníomhach an léitheora: 'Ní fhágtar tada faoin léitheoir.' Ar an taobh eile den scéal, 'ní hé gach léitheoir a bhrathas na hundertones ag na scríbhneoirí móra'. Is ag tagairt do bhrí mheafarach an ghearrscéil a bhí sé, ar ndóigh, brí a bheadh intuigthe agus inbhraite sa scéal ach gan míniú iomarcach tugtha ag an scríbhneoir oilte ar aon chuid faoi leith den scéal céanna. Filleann sé ar an ábhar seo sa dara litir sa chomhfhreagras seo, mar a bhfuil sé ag míniú a bhfuil ag tarlú laistigh den scéal 'Glantachán earraigh' don Duibhginneach, agus chítear go dtarraingíonn sé anuas coincheap na 'overtones' agus na 'undertones' arís. Leanann sé air:

Dúirt mé leat san léirmheas nach fuláir duit 'critical reading' a dhéanamh. Is sompla den rud atá i gceist agam an scéal seo. Níor léigh tú é critically. Chonnaic tú 'Glantáchán Earraigh' agus dúirt tú: 'seo é an Geimhreadh'. Annsin léigh tú thríd síos gan cuimhniú ar na rudaí a bhí taobh thiar de na línte, agus sin iad na rudaí is tábhachtaí i gcomhnaí i ndeá-scríbhneoireacht. Annsin dúirt tú 'níl baint ar bith aige seo leis an Earrach'. Sílim go dtiocfaidh tú liom anois go bhfuil agus an-bhaint. Ach ní thiúrfainn an míniú seo air marach go mb'fhéidir go gcuirfeadh sé ar an áirdeall thú faoi rudaí áiride.

Is díol suime an úsáid a bhaineann Ó Cadhain as téarmaí critice Béarla agus foirmeacha agus teicnící liteartha á bplé aige sa litir seo. Cé gur fhoilsigh an Roinn Oideachais an lámhleabhar téarmaíochta Téarmai gramadaighe is litridheachta sa bhliain $1930,{ }^{70}$ ní raibh foclóir údarásach Béarla-Gaeilge ar fáil trína

\footnotetext{
${ }^{69}$ Tá na sonraí faoi na craoltaí seo ar fáil in O’Leary, Irish interior, 411.

${ }^{70}$ An Roinn Oideachais, Téarmai gramadaighe is litridheachta (Baile Átha Cliath, 1930).
} 
scaipfí na téarmaí go forleathan go dtí gur foilsíodh English-Irish Dictionary Thomáis de Bhaldraithe sa bhliain 1959..1 Idir an dá linn, bhí téarmaíocht na critice á forbairt agus á saothrú ar bhealaí éagsúla ag scríbhneoirí na Gaeilge, agus spéis ar leith sa ghnó á léiriú ag leithéidí Liam Uí Rinn agus Néill Uí Dhónaill. Agus é ag tagairt do théarmaíocht na critice sa léacht 'Páipéir bhána agus páipéir bhreaca', áfach, léirigh Ó Cadhain amhras faoi obair sin na téarmaíochta:

Tá focla sa nGaeilge le tamall maith anois nach mór é mo ghnaoi-sa orthu 'léirmheastóir' cuir i gcás, nó 'amharclann' nó 'taibhdhearc'. Ach na focla a cuireadh in a n-áit le goirid, critic agus téatar is in a bhfocal Béarla a fhanfas siad go deo sa nGaeilge is cuma cén réim idirnáisiúnta atá acu. Tá chuile dhuine 'ag forbairt' mar deir siad féin. Ba mhó an chomaoin a chuirfeadh a lán acu ar an nGaeilge dhá mba ag buala golf a ghabhfaidís. $^{72}$

Tá an méid a deir Ó Cadhain i dtaobh údar nó ábhar scéil fíorshuimiúil sa mhéid go léiríonn sé an olltábhacht a shamhlaigh sé le ceantar dúchais, le muintir agus le hóige scríbhneora. Agus é ag comhairliú don Duibhginneach scríobh 'faoin rud a bhfuil a fhios agad', dearbhaíonn sé gurb é an 'chéad-bhiadh san sliogán duit an biadh is buaine, go fiú agus dhá mbeitheá imithe as le cianta. Féach Joyce, O'Casey, O'Flaherty'. Filleann sé ar an ábhar seo ina léacht 'Tuige nach bhfuil litríocht na Gaeilge ag fás?', áit a luann sé an tábhacht a bhaineann le taithí saoil agus le háit dúchais an scríbhneora:

\footnotetext{
${ }^{71}$ Tomás de Bhaldraithe, English-Irish Dictionary (Dublin, 1959).

${ }^{72}$ Ó Cadhain, 'Páipéir bhána agus páipéir bhreaca', 18-19. Ábhar taighde ar leith a bheadh i gceist úsáid na nuathéarmaíochta i saothar scríbhneoirí mar Ó Cadhain a scrúdú, ach tá sé suntasach gurb é an úsáid is coitianta a bhaineann sé as téarmaí critice Béarla sa léacht úd ná mar shoiléiriú ar bhrí coincheap atá aistrithe aige féin ón mBéarla (úsáid local organic community mar shoiléiriú ar 'comhthionól fuinniúil fuinte', mar shampla, innovator mar shoiléiriú ar 'nua-aosóir', anachronisms mar shoiléiriú ar 'iomraill aimsire', architypes mar shoiléiriú ar 'bunchlónnaí', the most plausible theory mar shoiléiriú ar 'an teoiric is sochreidte', canned speech mar shoiléiriú ar 'urlabhra cannaithe', nó medium mar shoiléiriú ar 'meán'). Nuair a roghnaíonn sé an téarma Béarla a úsáid gan leagan Gaeilge, is iondúil go bhfuil comhthéacs critice ar leith i gceist leis: literary tradition a phléann sé i gcomhthéacs shaothar T.S. Eliot, mar shampla, nó stream of consciousness a luaitear mar mhodh scríbhneoireachta díreach roimh thagairt do Ullysses Joyce. Is féidir breathnú ar úsáid an Bhéarla sa litir phearsanta chuig Ó Duibhginn mar thoradh ar lón léitheoireachta an Chadhnaigh i réimse na critice ar thaobh amháin, agus mar léiriú barántúil ar ghnás an chódmheasctha Gaeilge-Béarla ag dea-chainteoirí Gaeltachta.
} 
Ná scríobh faoi chogadh mura bhfuil do thaithí ar chogadh. Dá mhéad dá ngoilleann sé ar d'intinn níl in do mhothúchán ach mothúchán tacair ... Pé bith cén áit in Éirinn - Sligeach, Sandy Row, Béal Átha Dá Chab, Gloucester Diamond - ar oscail do shúil ar iontais an tsaoil, ar sceilpeog thú dá chré agus dá theampall, arb eolgach thú ar rún leathgháire ban agus feadaíl oíche fear, sin é an áit a bhfuil 'an grá' mar a deir Domhnall Ó Corcora. Mura n-éirí leat scéalta a fháisceadh astu sin, is cinnte nach bhfáiscfidh tú as aon damhna eile iad. ${ }^{73}$

Ba dhúshlán don Chadhnach saol na cathrach a léiriú ina shaothar cruthaitheach. Faoin am seo, bhí a chéad ghearrscéal cathrach scríofa aige, an scéal 'An t-aonú fleasc déag' a luaitear thuas, scéal a bhí ina réamhbhlaiseadh den léiriú duairc ar sheisce an tsaoil uirbigh sna mórscéalta cathrach a scríobhfadh sé ina dhiaidh sin agus a d'fhoilseofaí sna cnuasaigh An tsraith ar lár (1967), An tsraith dá tógáil (1970) agus An tsraith tógtha (1977). ${ }^{74}$ Chreid Ó Cadhain go diongbháilte nár chóir dó féin 'Baile Átha Cliath a fhágáil in a pháipéar bán. ${ }^{75}$ Dúirt sé in aiste ar an úrscéalaíocht a foilsíodh sa bhliain 1955 gur

... beag deacracht $\mathrm{i}$ saol an bhaile mhóir nach bhfuil a chomhdheacracht le sárú inniu ag an scríbhneoir sa nGaeltacht ... Is fada cuid againn ag rá nach bhfuil aon deacracht ná mínádúrthacht ar leith faoi chur síos a dhéanamh ar an mbaile mór. Caithfidh, dar ndóigh, fonn a dhéanta a bheith ort, thú taithithe ar an áit, taithithe ar do cheird agus taithithe ar an nGaeilge. ${ }^{76}$

Is léir óna shaothar liteartha féin, áfach, go raibh teorainn lena acmhainn dul i ngleic chruthaitheach leis na timpeallachtaí éagsúla sóisialta a thaithigh sé i gcaitheamh a shaoil. Tá an scéal mínithe go soiléir i dtéarmaí seánra sa litir seo: ' $D$ 'fhéadfainnse gearrscéalta a scríobhadh faoi rudaí áiride i mBaile Átha Cliath ach ní fhéadfainn uirscéal a scríobh fútha. Níl mo dhúchas ann.' Is ag caint le fear a bhfuil a dhúchas i gContae Ard Mhacha atá Ó Cadhain sa litir seo, áfach, agus tugann an chomhairle a thugann sé dó le fios gur chreid sé go bhféadfadh a leithéid de dhuine, nach fear Gaeltachta é, gnéithe éagsúla dá shaoltaithí a léiriú trí mheán na Gaeilge.

${ }^{73}$ Ó Cadhain, 'Tuige nach bhfuil litríocht na Gaeilge ag fás?', 93-4.

${ }^{74}$ Máirtín Ó Cadhain, An tsraith ar lár (Baile Átha Cliath, 1967); An tsraith dá tógáil (Baile Átha Cliath, 1970) agus An tsraith tógtha (Baile Átha Cliath, 1977).

${ }^{75}$ Ó Cadhain, 'Páipéir bhána agus páipéir bhreaca', 23.

${ }^{76}$ Ó Cadhain, 'Úrscéalaíocht', in Aindrias Ó Cathasaigh (eag.), Caiscín: altanna san Irish Times 1953/1956 (Baile Átha Cliath, 1998), 242. Céadfhoilsíodh an aiste seo san Irish Times ar 12 Eanáir 1955. 
Agus Ó Cadhain ag feidhmiú mar chomhairleoir liteartha ag Ó Duibhginn sna litreacha seo, chítear go gcuireadh sé líne faoi fhrásaí áirithe, mar shampla: 'Caifidh an scríbhneoir an rud a mhothú ina chroí' agus arís: 'caifidh scríbhneoir fuil a chroí a chur in a chuid scríbhneoireacht: an deóir deireadh dhi'. Ag cuimhneamh dúinn gur scríobh Ó Cadhain an litir seo in Eanáir na bliana 1947, is fú a thabhairt faoi deara gur foilsíodh aiste dar teideal 'Agus ba mhaith leat a bheith [i] do sgríbhneoir' le Séamus Ó Grianna in An Iris, Feabhra 1946, ina ndúirt Ó Grianna leis an té ar mhaith leis a bheith ina scríbhneoir éifeachtach go gcaithfeadh fuil a chroí a bheith sa scríbhneoireacht aige; 'an deor dheireannach de fhuil do chroidhe. ${ }^{97}$

Nuair a fhéachtar ar ábhar an ailt 'An gearrscéal sa Ghaeilge' a chuir Ó Cadhain ar fáil do Nollaig Mac Congáil le linn don Chadhnach a bheith ina aoiléachtóir in Ollscoil na Banríona 1966$7,{ }^{78}$ chítear gurb é an rud céanna nach mór atá á rá aige faoi sheánra an ghearrscéil is a bhí scríofa aige sa litir fhada seo a chuir sé chuig an Duibhginneach fiche bliain roimhe sin. Ar ndóigh, nuair a thug Ó Cadhain faoi thréithe an ghearrscéil chlasaicigh a áireamh agus a léirmhíniú do Ó Duibhginn agus, níos déanaí, dá lucht éisteachta agus léitheoireachta, ba iad saintréithe uilíocha an tseánra i gcoitinne a bhí á lua aige agus é ag plé an ábhair mar a dhéanfadh oide agus criticeoir coinsiasach dúthrachtach. Nuair a chuimhnítear ar na gearrscéalta a scríobh an Cadhnach féin sna daichidí tuigtear láithreach go raibh éirithe cheana féin leis an scríbhneoir ardchumasach seo feidhm mháistriúil a bhaint as féidearthachtaí ealaíne agus teicníce sheánra an ghearrscéil chlasaicigh agus, thairis sin, ba ríléir cheana féin go mbeadh réimsí ilchineálacha scéalaíochta agus scríbhneoireachta á dtriail agus á dtaiscéaladh go díocasach aige le go n-éireodh leis 'an rud is fearr atá Máirtín Ó Cadhain i ndon a dhéanamh' a thabhairt chun lánléargais. Faoi mar a scríobh Gearóid Ó Crualaoich:

... lean Máirtín air ag soláthar idir shleachta ar féidir gan stró ar bith iad a aithint mar 'ghearrscéalta', agus shleachta ar fearr déileáil le gach ceann acu díreach mar shliocht scríbhneoireachta ann féin, sliocht a bhíonn, de ghnáth, lán de pharadacsa na haoise ina mairimid - flosc gan foirm, fuinneamh gan fócas, faghairt gan fírinne, insint gan faoiseamh agus comhfhios gan sólás. ${ }^{79}$

\footnotetext{
${ }^{77}$ Séamus Ó Grianna, 'Agus ba mhaith leat a bheith [i] do sgríbhneoir', An Iris, iml.1., uimh.4 (Feabhra 1946), 33.

${ }^{78}$ Máirtín Ó Cadhain, 'An gearrscéal sa Ghaeilge', Scriobh 5 (1981), 100-5.

${ }^{79}$ Gearóid Ó Crualaoich, 'Domhan na cille agus domhan na bréige', Scríobh 5 (1981), 81 .
} 
Agus faoi mar a dhearbhaigh Alan Titley: 'D'aimsigh sé stíl agus foirm (nó neamh-fhoirm más maith leat) a bhí lánchothromúil dá shamhlaíocht agus dá chumas cruithníochta féin. ${ }^{80}$

Agus é ag trácht ar an easpa léirmheastóireachta ar an litríocht chomhaimseartha sa Ghaeilge sa léacht 'Tuige nach bhfuil litríocht na Gaeilge ag fás?' tagraíonn Ó Cadhain do thábhacht an chaidrimh phearsanta idir scríbhneoirí:

An treoir a thig as ceisteanna litríochta a chíoradh, as smaointe a shuaitheadh, as aighneas intleachtúil a chothú, níl sé ag an scríbhneoir Gaeilge. Ag sméaracht i bhfásall (vacuum) atá sé, nach bhfuil de ní tadhaill ann ach a chaondúthracht féin. ...

Go fiú an caidreamh pearsanta sin a chuidíos chomh mór le lucht litríochta, níl tada ar éigean de i measc scríbhneoirí na Gaeilge. Tá faitíos orm nach cabhair is mó atá siad seo sásta a roinnt le chéile, ní hionann sin agus na scríbhneoirí Béarla in Éirinn. ${ }^{81}$

Sampla den chineál cabhrach a d'fhéadfadh scríbhneoir a thabhairt d'ábhar scríbhneora atá sa litir atá foilsithe anseo. Léiríonn sé Ó Cadhain i mbun teagaisc, agus comhairle á tabhairt aige le croí maith mór, agus é ag súil go dtiocfaidh feabhas agus forás ar iarracht ghearrscéalaíochta Uí Dhuibhginn. Faoi mar a dhearbhaigh Ó Cadhain i dtosach na litreach seo: 'Rud ar bith atá le rá agam - agus tá a lán rudaí le rá agam nach mbaineann leis an scéal seo go háirid - siad na rudaí a chreidim féin agus a bhíos mar threóir agam iad.'

\section{Nóta eagarthóireachta}

Bheartaíomar an litir seo a fhoilsiú díreach mar a scríobhadh í, agus gan an Caighdeán Oifigiúil a chur i bhfeidhm ar theanga Uí Chadhain inti. Rinneamar an cinneadh seo ar an ábhar gur bhraitheamar nach gcruthódh an litriú neamhchaighdeánach deacrachtaí tuisceana do léitheoirí an lae inniu. Ar na leaganacha atá aige go coitianta tríd an téacs, tá: caifidh (in áit 'caithfidh'), coitiannta (coitianta), tiodal (teideal), athchuimre (achoimre), smaoineadh (smaoineamh), ag pléidh (ag plé), leó (leo), iomdha (iomaí), uirscéal (úrscéal). Chuireamar séimhiú isteach, idir lúibíní cearnacha, in áit amháin; chuireamar uaschamóga isteach idir lúibíní cearnacha ["] san áit a raibh siad in easnamh sna nótaí i dtreo dheireadh na litreach; agus chuireamar an focal 'tú' isteach in áit a raibh sé in easnamh. Is le Ó Cadhain féin na lúibíní cruinne, an t-uimhriú agus na folínte atá le feiceáil tríd an téacs.

${ }^{80}$ Titley, 'Máirtín Ó Cadhain agus foirm an ghearrscéil', 126.

${ }^{81}$ Ó Cadhain, ‘Tuige nach bhfuil litríocht na Gaeilge ag fás?', 91, 92. 


\title{
AN LITIR \\ Máirtín Ó Cadhain chuig Seosamh Ó Duibhginn, 6 EANÁIr 1947
}

\author{
58 An Cuarbhóthar ó dheas, \\ "An oíche a n-eiríonn an bodachán" 82
}

\begin{abstract}
A Sheosamh, a Chara,
Fuair mé do leitir agus "Folamhas Críochnaithe". D'iarr tú orm mo mheas a thabhairt air. Is contúirteach an rud a leithid a dhéanamh mar ní hannamh a chuireas sé deireadh le mórtas idir beirt. Rud ar bith atá le rá agam - agus tá a lán rudaí le rá agam nach mbaineann leis an scéal seo go háirid - siad na rudaí a chreidim féin agus a bhíos mar threóir agam iad. Ní fhágann sin go bhfuil siad ceart ná gur measadóir ar fónamh mise, ná ní shílim fhéin gurb ea.
\end{abstract}

1. An tiodiol - "Folamhas Críochnaithe". Ní abraím gur deá-thiodal ná droch-thiodal é. Taithníonn "falamhas" liom nó leagan eicínt a dtiocfadh "falamh" isteach ann. Ní thaithníonn "Folamhas Críochnaithe" liom. Tá sé rótheibí (ró "abstract". Ainm-fhocal abstract agus aidiacht abstract). Níor mhiste sin b'fhéidir dhá mba leagan teibí é a bheadh coitiannta i gcaint nó i litríocht nó a mbeadh blas nó tagairt liteardha ag gabhail leis. Caifidh tú a bheith anáirdeallach faoi thiodail. Is deacair a gcumadh. Níl aonmhaith i dtiodal a bhfuil athchuimre an scéil ann fearacht mar atá annseo nó fearacht "Leatroma na Cinniúna" agamsa nó cinn ar nós "An Grádh agus an Ghráin", "An t-Áthas agus an Brón" etc. Tiodal contúirteach é "Éad" nó “An t-Éad” cuirim i gcás, nó d'fheilfeadh sé b'fhéidir dhá mbeadh innseacht áirid ar an sgéal. Ní bheadh "Éad Cháit", "Éad an Oide" nó a mhacsamhail cho dona. Rud

\footnotetext{
${ }^{82}$ Oíche Nollag Beag, 6 Eanáir, atá i gceist leis 'An oíche a n-éiríonn an bodachán'. Seo mar a mhíníonn Tomás Ó Máille an nath in An béal beo: 'An oíche a ardaíos an bodachán, sin Oíche Nollag Beag. Is ionann an bodachán agus na haibhneacha a líonadh. Deirtear, má ardaíonn an bodachán Oíche Nollag Beag i dtús na hoíche, go mbeidh earraí daor i dtús na bliana' (Baile Átha Cliath, 2002), 38-9.
} 
eile faoi thiodail ná bídís do-thuigthe fearacht "An braon broghach" mar ainm leabhair agamsa ${ }^{83}$ Ach d'fhéadfadh tiodal a bheith diamhair nó go léifeadh duine an scéal ii. "The Monkey's Paw". ${ }^{84}$

B'fhearr a d'fheilfeadh "An Gortú" nó "An Chois Leónta" 85 nó a leithid don scéal seo b'fhéidir. Ná tabhair uait an scéal ar fad san tiodal.

2. Léigh mé an scéal fhéin dhá uair. An chéad-rud a thaithnigh liom nach bhfuil "an chríoch chleasach" (an trick-ending) agad. O Henry, Maupassant go minic, Séamas Ó Grianna i gcomhnaí. Más leat a fháil amach cén chaoi le gan scéal a scríobhadh, léigh leabhar nua Shéamais Uí Ghrianna (Scéal Úr 7 Sean-scéal). ${ }^{86}$ Tá sí agamsa. Ní fiú duit a ceannacht) nó gearr-scéal ar bith leis san gcás sin. Níl san leabhar ar fad ach aon-scéal amháin dháiríre cé go bhfuil sí roinnte in a dhá scéal déag. Aon phátrún amháin, aon deireadh amháin orra ar fad. Braifidh tú $i$ lár nó i dtús an scéil an deireadh a bhéas air. Plagiarism ar scéalta Frainncíse ${ }^{87}$ an chuid is mó acu (Eadrainn fhéin é seo. Rinne Séamas Ó Grianna gar domsa, agus ní ionnsóinn é. Déanadh duine eicínt eile é sin, cé nach bhfuil faitíos ar bith agam roimhe. Ar aon chor is aige is mó atá scríbhneoireacht déanta, cé nach fiú mórán cuid mhaith di). Ná bac leis an gcleas i ndeireadh an scéil. Tá an cineál sin scéil ar fad scríofa cheana. Ní féidir leatsa

\footnotetext{
${ }^{83}$ Foilsíodh An braon broghach, an dara cnuasach gearrscéalta le Máirtín Ó Cadhain, sa bhliain 1948. Oifig an tSoláthair a chuir amach. Cuireadh gluais leis an gcéad eagrán. Foilsíodh eagrán nua le gluais sa bhliain 1957 agus eagrán eile sa bhliain 1968 .

${ }^{84}$ Gearrscéal leis an scríbhneoir Sasanach W.W. Jacobs (1863-1943) a foilsíodh den chéad uair sa bhliain 1902 i gcnuasach scéalta leis dar teideal The lady of the barge (London \& New York). É athfhoilsithe in an-chuid cnuasach gearrscéalta ina dhiaidh sin. Baineann an gearrscéal seo le seánra na scéalta uafáis.

${ }^{85}$ 'An Chois Leointe' an teideal a bhí ar an ngearrscéal nuair a foilsíodh in eagrán mhí Iúil 1948 de Feasta é. Craoladh an scéal ar Raidió Éireann ar 6 Aibreán 1949 ('An Chos Leonta': clóscríbhinn de script chaint raidió i bhfoirm gearrscéil, Cartlann Scríofa RTÉ: Scripteanna Chaint Raidió i nGaeilge: P259, Cartlann an Choláiste Ollscoile, Baile Átha Cliath).

${ }^{86}$ Séamus Ó Grianna Scéal úr agus sean-scéal (Baile Átha Cliath, 1945).

${ }^{87}$ Bhí aistriúcháin ón bhFraincis á ndéanamh ag Séamus Ó Grianna sna daichidí, agus craoladh a leaganacha siúd de ghearrscéalta le Guy de Maupassant ('An ornáid', 2 Samhain 1943; 'M'Uncal Jules', g.d.); Alphonse Daudet ('Iomshuidhe Bherlin', g.d.; 'An Droch-Zouave', g.d.; 'An spiadóir óg', g.d.); François Coppée ('An fear ionaid', g.d.), agus Anatole France ('Cleasaidhe Mhuire', g.d.) ar Raidió Éireann ag tús na ndaichidí. (Cartlann Scríofa RTÉ: Scripteanna Chaint Raidió i nGaeilge: P259, Cartlann an Choláiste Ollscoile, Baile Átha Cliath).
} 
ná liomsa aon chleas nua a fháil. Agus ar aon-chor má chaitheann tú do scéal a chríochnú le cleas millfidh sé do chuid characterisation.

Sé an gearrscéal an dréacht nach mbíonn "scéal" ar bith ann ar an tsean-chaoi. Tá do scéalsa ceart ar an gcaoi sin.

3. Ag iarraidh rud eicínt a chur i gcion a bhíos scríbhneóir - smaoineadh amháin nó impression amháin ar intinn an léitheóra. Caifidh "iomlán ealaíonta" 88 a bheith san scéal: artistic whole and unity. Sin é an fáth go gcaifidh scríbhneoir toghadh agus gortghlanadh a dhéanamh ar a ábhar: cuid dhe a fhágáil ar lár, na puinntí cearta a thoghadh etc (na puinntí is mó a ghabhfadh i gcion ar intinn an léitheóra). Chítear dom go ndeachaidh tusa sách gar dó annseo ach ar chuma eicínt (agus sin é a dtig liom a rá) níl impression iomlán ann. Ní móide go ndearna tú do dhóthain staidéir roimh ré ar an ábhar le chuile shórt a dhéanamh beo agus gan a bheith ann ach rudaí beó.

Ná strachail an iomarca "atmosphere" isteach. An chéad alt agus an t-alt deireadh. Is cúnamh do scríbhneóireacht é "atmosphere" ach ní malrait. Dhá mbeadh an chuid eile den scéal ag cur leis an dá alt sin bheidís sin ceart.

Ná togha ach an "concrete" thríd agus thríd. Fág "abstractions" amach. Seachain "seanmóireacht". Ní "moralist" thú ach scríbhneóir. Cuir síos ar an saol mar atá sé agus ar dhaoine mar atá siad ach ná scríobh deilíní morálta faoin mianach atá san duine agus faoin mianach ba chóir a bheith ann. Ar ndóigh tá barúlacha morálta ag chuile dhuine faoin saol ach ní fuláir a gceilt mar rudaí gionarálta. Is scéalaí thú. Níl mé ag rá go bhfuil sin san scéal seo. Ach leagan ar nós "Ach ní hannamh an t-aintiarna lách ..." b' fhearr a rá san gcás sin mar is cineál deilín morálta é "Má b'aintiarna Cathal in a theach fhéin, ba duine lách é etc.” Tuigeadh an léitheóir an cás gionarálta. Tá tusa ag pléidh le duine amháin agus ní leis an gcine daonna mar Shíol Ádhaimhe.

4. Ná bac le samhaileanna ná cainteanna ná meafair sean-chaite. Tá Éire lán le cinn nua cinn dhúchasacha

\footnotetext{
${ }^{88}$ Is le teoiricíocht an scríbhneora Mheiriceánaigh Edgar Allan Poe (1809-1849) is mó a shamhlaítear an bhéim seo ar ghné na hiomláine ealaíonta agus ar éifeacht aontacht an imprisin sa ghearrscéal.
} 
cinn a bhfuil fírinne iontu, cinn a thuigeas chuile dhuine mar tá siad tíriúil gaelach (homely). Is deacair samhail a chruthú: an rud is deacra sa scríbhneóireacht b'fhéidir. Dante cuir i gcás tá samhail iontach aige san Inferno faoi na hanamnacha: sean-táilliúir caoch ag iarraidh snáth a chur i snáthaid. Sin samhail a thuigfeadh chuile dhuine in áit ar bith. Tá sí tíriúil. Ní bhíonn mo chuid samhaileanna fhéin thar mholadh beirte scaití. Ceann eile san dráma sin nar thaithnigh leat an "Cherry Orchard" $" 99$ : "an ghealach ag lonnra ar bhuidéal i sruthán an mhuilinn": concrete ar fad 7 rud atá ann.

Cotarsnaí freisin (: contrasts): asal dubh agus a thóin le balla aolnite aige.

Agus cuimhnigh go bhfuil cheire chéadfaí eile againn i dteannta na súl: baladh, blas etc. Bainfidh scríbhneóir leas asta ar fad.

Ní mór duit do chuid scéal a "dramatiseáil" agus an rud is mó san dráma teangmháil (conflict) nó codarsnaí (contrasts) - i dtaobh méin duine, áit etc.

Fuin an scéal in a chéile go maith. Ná bíodh tada ann ach a bhfuil ag tastáil. Dhá áilne an focal, an leagan, an tsamhail, an smaoineadh, bain amach iad mara call iad. Fóinfidh siad i rud eicínt eile aríst.

Is minic gurb é an rud fánach an taos fuinte is fhearr i scéal. Tá an rásúr i gceist i dtús an scéil seo. Níl inti ach rud fánach. Ach dhá dteagadh sí isteach aríst in a dheireadh: nach raibh gothadh an nirt ar rud ar bith anois ach ar an rásúr nó leagan eicínt den smaoineadh sin. Ar ndóigh i gcás den tsórt sin chaifeá an scéal a scríobhadh dhá réir. Caifidh tú na tuinnte beaga sin ar fad a c[h]rapadh suas san deireadh agus neartóidh siad ar fad an t-iomlán. Is beag rud a chaifeas tú uait i ngearr-scéal. Sin é an fá go gcaifidh tú gach rud a thoghadh thar cionn. ${ }^{90}$ Is

\footnotetext{
${ }^{89}$ Dráma de chuid an scríbhneora Rúisigh Anton Chekhov (1860-1904). Léiríodh an dráma in Amharclann an Gheata, Baile Átha Cliath, sa bhliain 1939 agus arís sa bhliain 1943. Tuilleadh eolais ar fáil ag: space.dial.pipex.com/town/parade/abj76/ PG/pieces/Chekhov_in_ireland.shtml (léite 18 Lúnasa 2014). D'fhoilsigh Oifig an tSoláthair An silin-ghort, aistriúchán Gaeilge le Maighréad Nic Mhaicín, sa bhliain 1935. Is díol suime go bhfuil tagairt do shamhail seo Chekhov i gceann de na haistí le Sean O’Faolain ar ealaín an ghearrscéil agus dhealródh sé ón méid a deir seisean gur ó litir de chuid Chekhov a tógadh an tsamhail áirithe sin (feic The Bell, Feabhra 1944, 406).

${ }^{90}$ Maidir le ceist seo roghnú cáiréiseach na sonraí a chuirfear isteach sa ghearrscéal, cuimhneofar ar an gcur chuige a dtugtar 'gunna Chekhov' mar achoimriú áisiúil air. Mar seo a chuireann H.E. Bates síos air ina leabhar The modern short story: a critical
} 
deacair na rudaí seo ar fad a mhíniú. Ach d'fhéachfainn len a theasbáint duit as cuid de na rudaí atá scríofa agam féin anois agus 'ar ndó' tá siad sna gearr-scéalta mór cuid Chekov, Tolstoi, Katherine Mansfield i Sasana, Ann Porter i Meiriocá, ${ }^{91}$ Frank O'Connor, Liam O'Flaherty agus eile.

5. Comhrá: Sé an cómhrádh an rud is cumasaí a léiríos méin agus cáilíocht daoine. Ná mínigh thusa - an scríbhneóir - céard atá in a n-intinn. Tabhair cead dóibh féin é a rá. Agus abraídís cho slachtar, agus cho snuite agus is féidir leó é.

Is iomdha rud a déarfas an scríbhneóir fhéin nach cóir dó ach leath-rá a thabhairt air: undertones. An locht is mó atá ar ghearrscéalta na Gaeilge an chuid is fhearr acu fhéin gur overtones ar fad iad. Deirtear an iomarca. Ní fhágtar tada faoin léitheóir. Ní hé chuile léitheóir a bhrathas na hundertones ag na scríbhneóirí móra. Ní dhéanfadh é ach scríbhneoir foirfe. Ní hionann an rud seo chor ar bith agus doiléaracht ná diamhracht. Fuil ar cheathrú madadh ag dul an bóthar : cruthú go raibh sé i ndiaidh gadhar adhaill. Ach b'fhéidir san am céanna narbh ea. Sin de réir an scéil nó an bharúil a bhainfeas an léitheóir as.

6. Seachain comharthaí ar nós ** idir míreanna den scéal. Is deacair a seachaint scaití ach déan é más féidir chor ar bith. Figh an scéal in a chéile ó thús go deireadh. Tathaigh alt leis an alt in a dhiaidh agus mar sin. Is fhearr an chuma a d'fhága fear an Phress ar do scéal ná a d'fhágfadh fear an Independent air len a chuid tiodail ailt. Mhill sé rud a bhí agamsa ann an lá cheana le tiodail mar sin agus le athchinn-tiodal - "Achainí na Sean" ${ }^{92}$ Ní mise a chuir é sin ann dar ndóigh.

survey: '... [Chekhov] reminded authors that if they described a gun hanging on the wall on page one, sooner or later that gun must go off' (London, 1941), 16.

${ }^{91}$ Is í an gearrscéalaí Meiriceánach Katherine Anne Porter (1890-1980) atá i gceist ag an gCadhnach anseo. Agus H.E. Bates ag trácht ar Porter, deir sé: 'In a sense she is the most accomplished writer, yet not the most individual writer, of the short story in America to-day' (London, 1941), 185.

${ }^{92}$ Tá Ó Cadhain ag tagairt anseo don ghearrscéal 'Glantachán earraigh' a foilsíodh san Irish Independent ar 23 Nollaig 1946, agus an t-ath-theideal 'Achainí na sean' curtha leis ag eagarthóir na míre. Foilsíodh leagan 'maisithe' den scéal in Feasta Márta 1951,8-9. Ba é an chéad leagan den scéal a foilsíodh sa chnuasach Cois caoláire (Baile Átha Cliath: 1953), 9-11. 
7. Idtaobh údair nó ábhair scéil: Scríobh faoin rud a bhfuil a fhios agad. Bíonn eolas ar intinn na ndaoine san gceanntar ar tóigeadh é ag duine. Sén chéad-bhiadh san sliogán duit an biadh is buaine, go fiú agus dhá mbeitheá imithe as le cianta. Féach Joyce, O'Casey, O'Flaherty. D'fhéadfainnse gearrscéalta a scríobhadh faoi rudaí áiride i mBaile Átha Cliath ach ní fhéadfainn uirscéal a scríobhadh fútha. Níl mo dhúchas ann. Tá traditions eile ag na daoine seo cé gur Éireannaigh iad nach mothaímse. Caifidh scríbhneóir an rud a mhothú ina chroí cé go mb'fhéidir nach nglacfadh sé leis de bharr athrú intinne etc. Ní mhothóidh duine i gceart ach an rud atá i gcroí a mhuinntire fhéin. Tá sé fánach againn a bheith ag scríobhadh filíocht faoi Stalingrad. Deir duine eicínt le goirid go raibh an iomarca scéalta againn faoi iascairí agus faoi ghleannta agus sléibhte (an iomarca droch-scéalta adéarfadh sé dá mbeadh aontuigsint ann - rud nach bhfuil) agus go mba cheart scéalta a scríobhadh faoi stát-sheirbhísigh, sagairt etc. Ach ní san Stáit-sheirbhís ná san Eaglais (sin a deirtear ar chaoi ar bith!) a bheirtear ná a tóigtear aonduine. Agus ní hé an rud a níos stáit-sheirbhíseach le comhad ná sagart lena $\mathrm{p}[\mathrm{h}]$ ínneachaí Peadair ${ }^{93}$ a chomhaireas san litríocht. Baineann an litríocht inniu mar a bhain sí aimsir Homer le breith agus le bás, grádh agus brón, éad agus aicís, cogadh agus teangmháil, gaisce agus cladhairíocht 7 a leithide. Sin iad na rudaí buanna san duine cé go mb'fhéidir nach mbeadh stáit-sheirbhísigh ná sagairt ann faoi cheann céad bliain. Ní hionann sin agus a rá nar cheart cur síos ar stáitsheirbhísigh agus sagairt. Ach ní i ngeall gur sagairt ná stáitsheirbhísigh go háirid iad. Is beag is inspéis duine in a stát-sheirbhíseach ná in a shagart ann fhéin. Ach is inspéis é i ngeall ar a chroí agus na rudaí a fhéachas sé le déanamh etc.

Tá sleid ${ }^{94}$ ar litríocht na Gaeilge san méid gur faoin

\footnotetext{
${ }^{93}$ Glacaimid leis gurb é bailiúchán bliantúil na hEaglaise Caitlicí, 'Peter’s Pence' sa Bhéarla, atá i gceist ag an gCadhnach anseo. Gach bliain, ar an Domhnach is gaire do 29 Meitheamh, lá fhéile Naomh Peadar agus Naomh Pól, iarrtar ar Chaitlicigh síntiús ar leith a thabhairt do bhailiúchán an Phápa chun cabhrú leis an Eaglais freastal ar riachtanais mórán pobal a bhfuil cúnamh praiticiúil de dhíth orthu. Tuilleadh eolais le fáil ó: www.vatican.va/roman curia/secretariat state/obolo spietro/document/ actual.en.htm (Léite 18 Lúnasa 201̄).

${ }^{94}$ 'Folach' nó ‘clúdach' nó ‘craiceann' atá i gceist le 'sleid', ach is léir sa chomhthéacs seo gur ag caint go meafarach atá Ó Cadhain agus é ag cur in iúl go bhfuil easpa éigin ar an litríocht, go bhfuil sí in uireasa ruda éigin. Táimid fíorbhuíoch den Dr Ciarán Ó
} 
nGaeltacht is mó a bhfuil againn di. Dhá mbeadh an Ghaeltacht ar fud na hÉireann ní bheadh sin amhlaidh, nó dhá scríobhadh Gaeilgeoirí arbh fhíor Bhaile Átha Cliathachaí nó fíor-Mhidheachaí, nó fíor-Achréidheachaí iad leabhra Gaeilge. Sin rud a thig leatsa agus le do leithide a dhéanamh. Tá do dhúchas in áit eicínt thíos i gCo. Árd Mhacha. Annsin a tóigeadh tú. Tig leat scríobhadh faoi. Tig leat scríobhadh faoi na daoine a casadh leat i Sasana, in Albain etc. a bhfuil tú ag obair leó i mBaile Átha Cliath, a bhí i ngéibheann leat san gCurraigh etc. Ach caifidh tú eólas agus tuigsint agus léargas a bheith agat i gcomhnaí faoin dream a scríobhann tú fútha. Ná scríobh faoi dhaoine nó faoi dhreamanna den phobal nach bhfuil eólas agad orra (dar ndóigh ní abraím gurb amhlaidh atá sé san scéal seo).

8. Déan do dhícheall le gach rud dhá scríobhfaidh [tú] agus ná lig uait é go mbí sé cho foirfe slachtar agus a thig leat a dhéanamh. B'fhéidir taréis do sheacht ndícheall nach mbeadh sé sách maith ná sách foirfe. Ní coir ná peacadh é $\sin$. Ach is coir agus is peacadh é rud a ligean uait nuair nar chaith tú do dhóthain dúrachta leis nó nuair a d'fhéadfá feabhas a chur air. Ná bí sásta go deó le do shaothar fhéin. Is droch-theastas [é sin] ar scríbhneóir. Níl rud ar bith cho maith 7 nach féidir a fheabhsú tuilleadh. Caifidh scríbhneoir fuil a chroí a chur in a chuid scríbhneóireacht: an deóir deireadh dhi. Tá mise cinnte nach scríobhfaidh mé scéal go deó cho maith le Chekov, ach má chuirim an rud is fearr atá Máirtín Ó Cadhain i ndon a dhéanamh in mo chuid scríbhneóireacht, beidh mé sásta, ach mar ndéana mé sin gheobhaidh mé bás míshásta. Is saol cruadh anróiteach agus is obair léanmhar í obair scríbhneóra: aon chineál scríbhneóra. "One percent genius. 99\% sweat". ${ }^{95}$

Tá barúil agam dhá nglactha tuilleadh ionú leis an scéal seo go ndéanfá scéal níos fhearr dhe.

\section{Puinntí eile faoin Scéal:}

Ní mheasaim go bhfuil an tús ro-mhaith, san áit a n-innsíonn tú faoi theacht isteach an fhir. "Agus shiúil

\footnotetext{
Coigligh as brí an fhocail seo a shoiléiriú dúinn.

${ }^{95}$ Leagan den ráiteas cáiliúil a rinne an t-innealltóir Thomas A. Edison, 'Genius is one percent inspiration, ninety-nine percent perspiration'.
} 
go torann isteach ...." Annsin innsíonn tú faoin a chuid oibre, agus deir tú aríst "ar a theacht isteach dó leag sé etc.["] Tá an ghluaiseacht bearnaithe. Agus ó nar dhúirt mé sin cheana, ba cheart go mbeadh gluaiseacht as éadan i scéal ó thús go deireadh. Gluaiseacht as a chéile. Tosaigh an scéal san áit a bhféadfaidh tú an ghluaiseacht sin a thionnscailt. Is olc an rud a bheith ag dul siar i scéal le eolas a thabhairt uait faoi rudaí a thárlaigh roimhe sin. Ní féidir a sheachaint scaití, ach ní ceart a dhéanamh ach a laghad agus a fhéadfas tú. Ní shin locht atá ortsa amháin. Tá sé orainn uilig. Bhí sé ar Phádraig Ó Conaire. Tá Séamas Ó Grianna lán leis. D'fhéadfá an t-eólas seo faoin a chuid oibre a thabhairt isteach in áit eicínt eile agus níor chall dó a bheith cho fada b'fhéidir: san áit a raibh sé dhá bhearradh fhéin, nó i ndiaidh an chéad ailt agus é ar a bhealach abhaile gur airigh sé an cruas san tránóna. É a shnadhmadh leis an gcéad alt.

An t-alt seo dár tús: "Ach má d'ith sí an oiread sin bídh ...”: é sin a ghiorrú. Féach len a dhéanamh d'aonscríb amháin. A dhalta sin an giota dar tús: "Deiridís san a raibh aithne acu uirri .... ba ceann de na hoícheanntaí í a gcuirfí cearc ar cártaí.” Tá sé ró-fhada. Ní call an t-eolas seo ar fad. Rud eile ní hé an t-eólas is beócha é cés moite den chirc fhéin. An rud a bhí ag tastáil ansin cotarsna dhá bhean fhéin; garbhóg mhór láidir de bhean a dtug sé taithneamh drúisiúil di (cé nach n-abhróchthá sin). Ach níl caint ar bith agad ar a méid ná a tréara.

"Ach faraor!" Ná déan tusa truaigh den duine. Ní bhaineann sin duit. Innis céard a thárla agus sin é an méid.

Tá scríb bheó eicínt ar iarraidh ag deireadh an dara halt deireadh: "Ach níor mhair sin ach seal. Traoch sí cho sciobtha etc.["] Ní thaithníonn "ba gheall le deilbh chré í" liom gan rud eicínt roimhe nó in a dhiaidh. Annsin atá deireadh an scéil dháiríre agus níor mhór rud ann a cheadódh an t-alt deireadh a chur isteach.

Puinntí faoin gcaint: "Agus rud a chuir barr iontais uirri etc." Tá an rá cainte sin ro-fhada ro-liopastach agus is "broken-back sentence é .i. dhá ag fiafraí di ... ag fiafraí di”. Tá a leithide ag Séamas Ó Grianna go minic ach seachain é.

"A d'fhiafraigh sé go harannta" ... "arsa sise go neámhaí.["] Ní contrasts ro-mhaith iad sin. Tuigim gur 
theastaigh an smaoineadh san scéal, ach tá siad ró-mhór ar an múnla céadna ... "go + aidiacht ... go + aidiacht["] dhá n-innsightheá roimhe sin nó dhá dhá n-abruightheá annseo féin "arsa sise dhá glór neamhaí.["] Ach b'fhearr go hiondúil gan a bheith ag míniú comhrá ar an gcaoi sin le aidiacht. Cleas é atá sean-chaite. A thabhairt isteach roimhe sin, nó múnla a chur ar an gcómhrá go dtuigfí uaidh cén sórt glór a bhí aici agus aige dhá rá.

"Agus más carthannach gan an fhírinne etc ... riocht.” Tá sé ro-phuinnteáilte annseo. Bheadh sé ceart go leór i scéal grinn nó in áit a mbeadh greann de chineál áirid ag teacht isteach i scéal, ach is stúáil (: padding) mí-thaithneamhach annseo é. Tosaigh: "Ní mór a innseacht etc ..."

"Dúirt leis roinnt aca a thabhuirt dom, ach ní thabharfadh sé ceann ar bith dhom.["] ("Níor thug sé ceann ar bith dhomsa" go dlúth in a dhiaidh): tá seo míthaithneamhach. "Agus dúirt leis roinnt liomsa" nó rud mar é. Bí san áirdeall gan na focla céanna a bheith romhinic agad ná fiú agus na fuaimeannaí céanna: ("sheas", "a gheall" cuirim i gcás dlúth le chéile). Ná tosaigh sraith abairt i ndiaidh a chéile le briathar san aimsir chaite cuirim i gcás. Tosaigh ceann le briathar ceann le ainm-fhocal etc. ("tá" i dtosach. "is" i dtosach etc).

"Bíodh sé fíor contráilte, b'é barúil Chathail - agus is minic adúirt sé suas lena béal é - nach ( ) ${ }^{96}$ mar seo.[”] an taobh eile den bhord ... don bhord (ro-dhlúth le chéile) ar ais ... ar ais ag an ceathair (ro-dhlúth le chéile)

chuala ... chuala ro[-dhlúth] le chéile

"Ach ní dual sleachta ... an cineál dár díobh tú": tá "tautology" annseo. Tuilleadh agus do dhóthain ráite. Dúradh san gcéad chuid ("dual sleachta") an rud atá san dara cuid agus níor chall an dara cuid a bheith ann chor ar bith. Ach ní mheasaim go bhfuil an focal sliocht ceart. Sinnsear ba chóir a bheith ann.

ile: tuige nach "ola". Ní mise a mhúin "íle" duit. ${ }^{97}$

Trufán: canúnachas: tnuthán

D'innis a dúchas banúil di ... Sin ceann de na rudaí gionarálta a bhí i gceist agam ní ba thúisce san gcomhairle seo. B'fhearr liom a rá cé nach mbreathnaíonn sé cho deas: "Thuig sí in a croí istigh ..." nó "thuig sí ó ba bean î"

\footnotetext{
${ }^{96} \mathrm{Ní}$ rabhamar in ann an focal seo sa téacs a dhéanamh amach ón lámhscríbhinn.

${ }^{97}$ Tagairt do ról an Chadhnaigh mar mhúinteoir Gaeilge sa Churrach.
} 
"ar a éadan"... éadaigh : an dá fhuaim éadh ro-dhlúth.

a cuireadh i ngreamús : a bhí i ngreamús nó "a raibh greamús ar an mballa air le táirní.["] Bí áirdeallach faoi bhriathra mar sin go háirid san aimsir chaite. Ó dúirt tú cuireadh ann bheadh duine ag súil go n-abróchthá gur anuiridh nó inné nó am áirid eicínt a rinneadh é.

"nuair a bhí sé in a lá" - "Chomh uain agus a bhí an lá ann (agad)". "Nuair a bhí sé in a lá": when day broke, when day dawned.

spurha de thobac: ní ag fanacht a bheitheá go mbeadh mo chuid tobac spurha (nó ídithe).

Tarraingteach : ní thaithníonn an focal seo liom cé gur feasach mé go bhfuil sé ann.

Sin é a bhfuil le rá agam faoi. Ní fiú mórán mo bharúil-sa. Chuaigh mé thríd cho grinn agus a d'fhéad mé agus amhdaím go raibh mé ag tóraíocht locht. Ach sin é a d'iarr tú orm a dhéanamh. Marach gur shaoil mé gurbh fhiú an saothar é, ní chuirfinn an méid seo anró orm fhéin. San am ar thosaigh mise ní raibh agam ach dhá chineál duine: an duine adúirt go raibh mo chuid saothair ar an gcéad scoth agus an té údan eile adúirt gurb é díogha na ndíogha é. Níorbh é an chéad-scoth é, ná an dara scoth, ach measaim anois fhéin gurbh fhiú rud eicínt é, cé go raibh an iomad locht air.

Níl do shaothar-sa ar an gcéad-scoth ach oiread. Ainneóin sin déarfaidh mé seo. Tá an scéal seo go maith. Ach d'fhéadfadh sé a bheith níos fhearr agus bhí tú acmhainneach ar a dhéanamh ní b'fhearr dhá scríobhthá cupla uair eile é. Agus measaim go bhfuil tú indon saothar cho maith agus atá san nGaeilge a dhéanamh ach caitheamh leis agus leis nó go mbí sé ar deil agad. Ní mór duit léitheóireacht a dhéanamh freisin. An chéadscoth. Ná léigh ach an chéad-scoth. Ní bheidh tú ach ag milleadh t'intinne le tada eile. Baineann "tell me your company" le leabhra cho maith agus a bhaineas sé leis an saol. Léitheóireacht roighin a gcuirfidh tú cronaí i[n]s gach rud nach mór duit a dhéanamh. Ní hé an oiread sin léitheóireacht is gá do scríbhneóir ach í a bheith ar an scoth. An chéad-scéal eile a scríobhfas tú tabhair chugam é agus pléifeamuid é nuair a bhéas sé scríofa ar do shástacht fhéin.

Mise

M. Ó Cadhain 